Natural Hazards and Earth System Sciences (2003) 3: 757-776

(C) European Geosciences Union 2003

Natural Hazards and Earth System Sciences

\title{
Regional seismic hazard for Revithoussa, Greece: an earthquake early warning Shield and selection of alert signals
}

\author{
Y. Xu ${ }^{1}$, P. W. Burton ${ }^{1}$, and G.-A. Tselentis ${ }^{2}$ \\ ${ }^{1}$ School of Environmental Sciences, University of East Anglia, Norwich NR4 7TJ, UK \\ ${ }^{2}$ Seismology Laboratory, University of Patras, Rio 261 10, Greece
}

Received: 16 June 2003 - Revised: 19 August 2003 - Accepted: 22 August 2003

\begin{abstract}
The feasibility of an earthquake early warning Shield in Greece is being explored as a European demonstration project. This will be the first early warning system in Europe. The island of Revithoussa is a liquid natural gas storage facility near Athens from which a pipeline runs to a gas distribution centre in Athens. The Shield is being centred on these facilities. The purpose here is to analyze seismicity and seismic hazard in relation to the Shield centre and the remote sensor sites in the Shield network, eventually to help characterize the hazard levels, seismic signals and ground vibration levels that might be observed or create an alert situation at a station. Thus this paper mainly gives estimation of local seismic hazard in the regional working area of Revithoussa by studying extreme peak ground acceleration (PGA) and magnitudes.
\end{abstract}

Within the Shield region, the most important zone to be detected is WNW from the Shield centre and is at a relatively short distance ( $50 \mathrm{~km}$ or less), the Gulf of Corinth (active normal faults) region. This is the critical zone for early warning of strong ground shaking. A second key region of seismicity is at an intermediate distance (100 km or more) from the centre, the Hellenic seismic zone south or southeast from Peloponnisos. A third region to be detected would be the northeastern region from the centre and is at a relatively long distance (about $150 \mathrm{~km}$ ), Lemnos Island and neighboring region. Several parameters are estimated to characterize the seismicity and hazard. These include: the 50-year PGA with $90 \%$ probability of not being exceeded (pnbe) using Theodulidis \& Papazachos strong motion attenuation for Greece, $\mathrm{PGA}_{\mathrm{NTP}}$; the 50-year magnitude and also at the $90 \%$ pnbe, $\mathrm{M}_{50}$ and $\mathrm{M}_{\mathrm{P} 50}$, respectively. There are also estimates of the earthquake that is most likely to be felt at a damaging intensity level, these are the most perceptible earthquakes at intensities VI, VII and VIII with magnitudes $\mathrm{M}_{\mathrm{VI}}, \mathrm{M}_{\mathrm{VII}}$ and $\mathrm{M}_{\mathrm{VIII}}$. Example results (from many) include the corresponding parameters describing the hazard for Revithoussa as follows: PGA $A_{\mathrm{NTP}}: 203 \mathrm{~cm} \mathrm{~s}^{-2}, \mathrm{M}_{50}: 6.5, \mathrm{M}_{\mathrm{p} 50}: 6.9, \mathrm{M}_{\mathrm{VI}}: 5.8$,

Correspondence to: Y. Xu (y.b.xu@uea.ac.uk)
$\mathrm{M}_{\mathrm{VII}}$ : 6.1 and $\mathrm{M}_{\mathrm{VIII}}$ : 6.4. These data are also useful in selecting expected alert-signals i.e. examples of strong ground vibration histories that might be expected at a Shield station in the alert situation.

\section{Introduction}

Earthquake early warning or earthquake real-time warning systems use modern technology to attempt to estimate earthquake parameters during the actual faulting process. It calculates earthquake strong motion (usually ground acceleration) by detecting the first elastic wave of the sequence that arrives from an earthquake. It can issue a warning prior to the arrival of the damaging secondary wave for the facilities far enough from the seismic source if a dangerous threshold is exceeded. The leading time is from a few seconds up to 1$2 \mathrm{~min}$. The early warning system for Mexico City was successfully tested by a large earthquake (7.3 $\mathrm{M}_{\mathrm{S}}, 14$ September 1995) by giving warning information $72 \mathrm{sec}$ before the arrival of strong ground motion (Espinosa et al., 1995).

Our "SHIELDS" (Safeguarding Hydrocarbons Inside Earthquake Local Defence System) project funded by CEC (Commission of the European Community) is to design a demonstration earthquake early warning Shield) and provide an earthquake early warning signal for the Revithoussa hydrocarbon site in Greece (Figs. 1a-b). Revithoussa Island is about $20 \mathrm{~km}$ from Athens. It contains liquid gas storage vessels, pipelines and related technology. It is the key infrastructure providing delivery of gas to urban units in Athens. It will continue to be developing in that oil and gas pipeline is being constructed in Greece to bring hydrocarbons into EC from European and non-EU countries. Therefore this earthquake early warning shield is important. This CEC demonstration project will be the first early warning system in Europe; nearby an early warning system is being prepared to help protect Istanbul (Erdik et al., 2003). The Shield is being centred on these facilities in the island of Revithoussa. The purpose here is to analyze seismicity and seismic hazard in 
relation to the Shield centre and the remote sensor sites in the Shield network, eventually to help characterize the hazard levels, seismic signals and ground vibration levels that might be observed or create an alert situation at a station. Thus this paper mainly gives estimation of local seismic hazard in the regional working area of Revithoussa by studying extreme PGA and magnitudes. In other words, this estimation contains two major parts of the study. The first is the hazard analysis based on the extreme magnitude by the third Gumbel model and earthquake perceptibility around the gas storage site (Revithoussa). The second is the study of local ground acceleration hazard of the working area, based on free-zonation, using the first Gumbel model.

\section{Shield regional working area of Revithoussa and data}

Generally, the engineering seismic influence from the region beyond $200 \mathrm{~km}$ away from a site can be ignored. Based on this principle, the region $\left(35.50^{\circ}-40.00^{\circ} \mathrm{N}, 21.00^{\circ}-\right.$ $25.50^{\circ} \mathrm{E}$ ) is selected for this study for the Revithoussa hydrocarbon site $\left(37.961^{\circ} \mathrm{N}, 23.404^{\circ} \mathrm{E}\right)$ (Fig. 1). Extreme strong ground motion and magnitude occurring in the region $200 \mathrm{~km}$ around the site will be studied.

First we update the MB earthquake catalogue for Greece 1900-1978 (Makropoulos and Burton 1981; Makropoulos et al., 1989) to include 1979-1999 (Burton et al., 2003c). The basic references for this updated work are ISC, NEIC and CMT Harvard catalogues. NOA (National Observatory of Athens) catalogue was consulted for the most recent events. Engdahl et al. (1998), Préez (1999), and some Greek seismologists (Papazachos and Papazachou, 1997; Margaris and Papazachos, 1999; Baba et al., 2000) were also consulted to improve basic qualities such as accuracy, completeness and homogeneity. This updated catalogue is used to compute peak ground acceleration at a point of interest associated with each event. Generally speaking, the earthquake records (1900-1999, $\left.\mathrm{M}_{\mathrm{S}} \geq 5.5\right)$ for Greece can be regarded as complete samples of data (e.g. Makropoulos and Burton 1981; Makropoulos et al., 1989; Papazachos and Papazachou, 1997; Papaioannou and Papazachos, 2000). We use these records for analysis in this paper.

\section{Hazard analysis of extreme magnitude and earth- quake perceptibility}

\subsection{Methods}

- Extreme magnitude from Gumbel III model Gumbel's third asymptotic distribution of the extreme values (Gumbel, 1966) has long proven to be suitable to describe seismic activity, one reason being the existence of an upper limit to the extreme value for magnitude:

$$
G^{I I I}=\exp \left[-\left(\frac{\omega-m}{\omega-\mu}\right)^{\frac{1}{\lambda}}\right]
$$

where $\omega$ is this upper limit to magnitude occurrence, $m$ the extreme magnitude in a unit interval (typically one year interval), $\mu$ is the characteristic extreme magnitude value, $\lambda$ describes the curvature of the distribution and $G^{I I I}$ stands for probability in the Gumbel's third model. As mentioned above, if the sample interval is set to be $T$ years, rather than annual, and the samples are independent of each other, then the relation (1) can be written as:

$$
G_{T}^{I I I} \rightarrow\left(G^{I I I}\right)^{T}=\exp \left[-T\left(\frac{\omega-m}{\omega-\mu}\right)^{\frac{1}{\lambda}}\right]
$$

The probability density $\rho$ can thus be obtained:

$$
\rho=\frac{d G_{T}^{I I I}}{d m}=T(\omega-\mu) / \lambda G_{T}^{I I I}\left(\frac{\omega-m}{\omega-\mu}\right)^{1 / \lambda-1}
$$

from which the most probable magnitude over the time interval $T$, by setting $\frac{d \rho}{d m}=0$, is (Makropoulos and Burton, 1985a):

$M_{\text {prob }}=\omega-(\omega-\mu)\left(\frac{1-\lambda}{T}\right)^{\lambda}$.

Then the extreme magnitude $m$ in the $T$-year interval has a probability of $\left(G^{I I I}\right)^{T}$ and can be calculated as:

$$
m=\omega-(\omega-\mu)\left[-\ln \left(G_{T}^{I I I}\right) / T\right]^{\lambda} .
$$

\section{- Perceptibility}

Earthquake perceptibility is defined to be the probability that a site perceives ground shaking at least of intensity $I$ arising from, i.e. conditional on, an earthquake occurrence of magnitude $M$ (Burton, 1978, 1990), i.e.:

$$
P(I / M)=P_{c}(I) P_{e}(M)
$$

The term $P_{c}(I)$ estimates the probability of perceiving intensity level $I$ from a magnitude $M$ earthquake, this will increase with magnitude, and can be considered as a ratio of the felt area at intensity $I$ or greater to that of the given area investigated. The felt area at intensity $I$ can be obtained from the local macroseismic attenuation relationship. Papazachos and Papaioannou (1997), on the basis of macroseismic field investigation of the shallow earthquakes in the Balkan area, using a large sample of macroseismic data, suggested that the macroseismic intensity at a site is a result of anisotropic radiation at the seismic source, geometrical spreading and anelastic attenuation along the wave path. They suggested the following attenuation relation for shallow earthquakes:

$I=1.43 M-3.59 \log (R+6)+2.26$ 

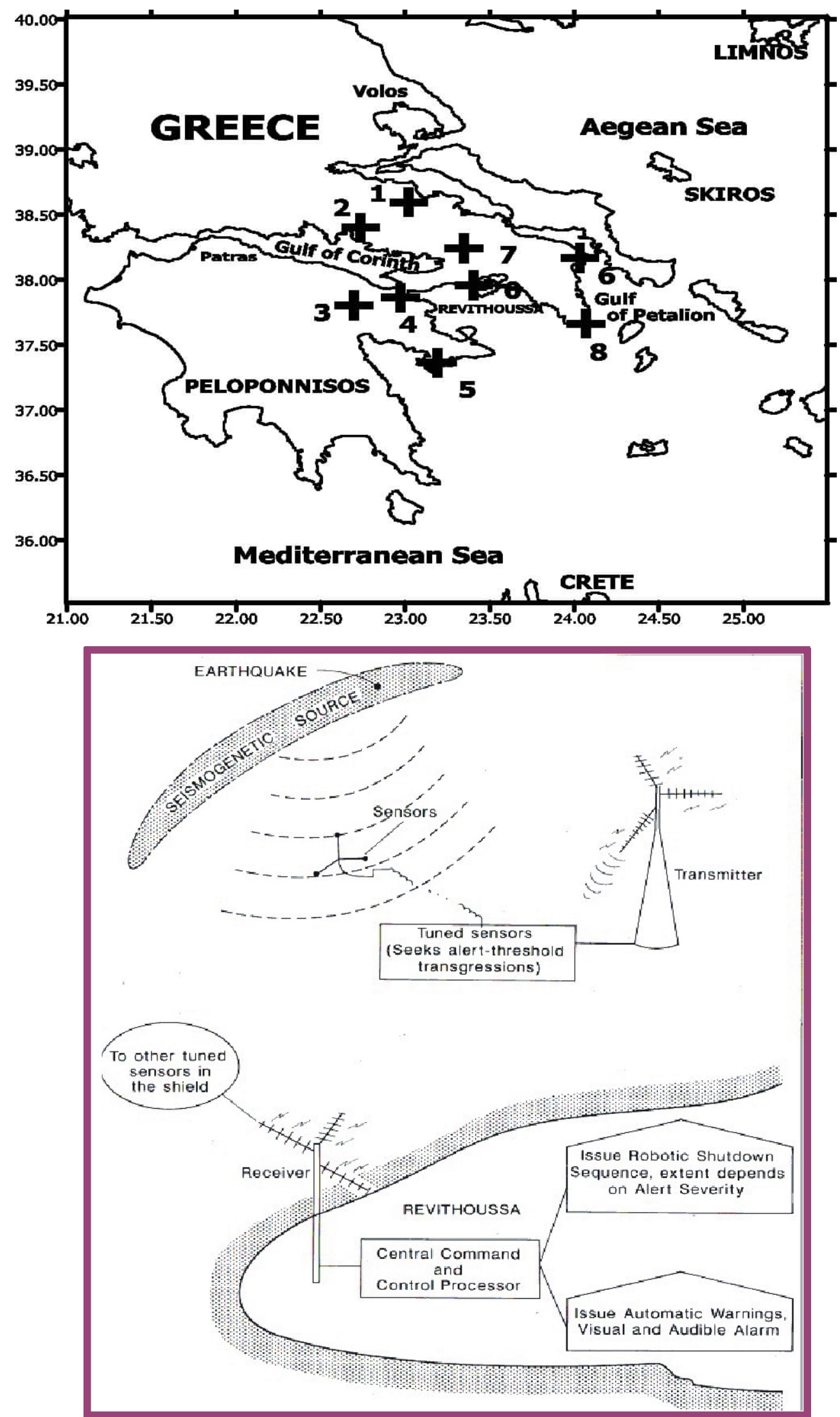

Fig. 1. (a) The regional working area of Revithoussa and Shield seismic alert stations numbered 0-8 and marked +; (b) Elements in the SHIELD early warning network around Revithoussa. 


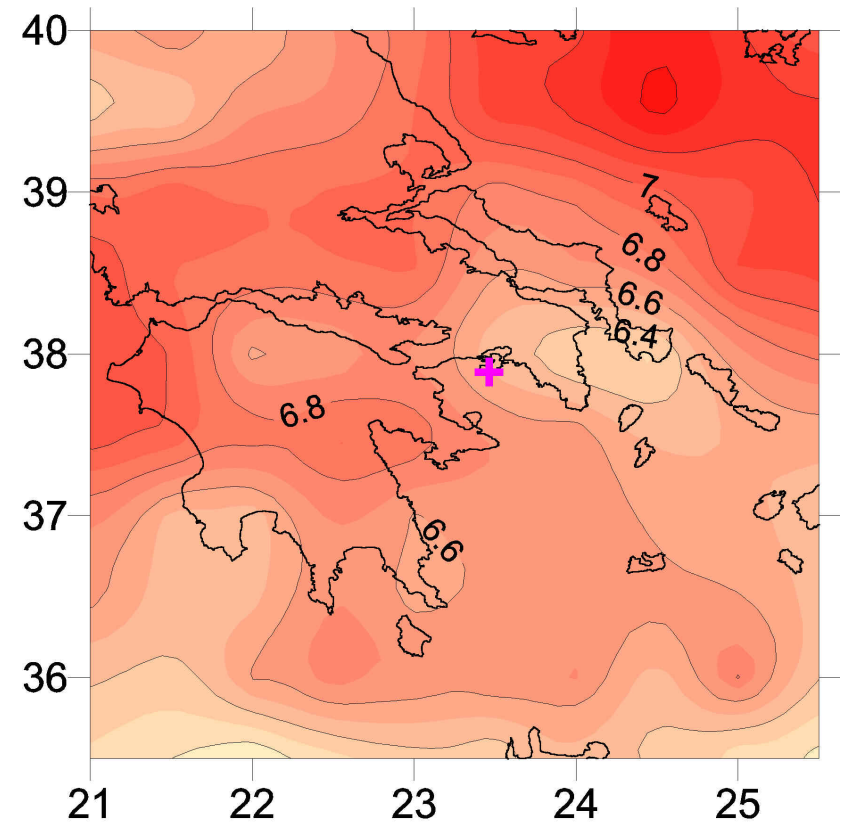

Fig. 2. The largest magnitude expected over the time period of 50 years for the Revithoussa working area.

where $I$ is the intensity on the MM scale, $M$ is the corresponding moment magnitude and $R$ the epicentral distance in kilometer (Papaioannou and Papazachos, 2000). Although Eq. (7) was derived using MM intensities, it should be noted that the intensities defined by the recently introduced European Macroseismic Scale 1998 (EMS-98 Scale) are not significantly different. The EMS-98 is the most recent adaptation of the previous intensity scales. The term $P_{e}(M)$ is the derivative (probability density) of the third asymptotic law and estimates the probability of a magnitude $M$ occurrence. The magnitude which is most probably felt at a site at intensity level $I$ or higher corresponds to the largest value of Eq. (6) i.e. where

$\frac{d[P(I / M)]}{d M}=0$

This is the condition that defines the "most perceptible earthquake". In other words, this determines the earthquake that is most likely to be perceived or felt at any level of ground motion at a site or in a region and is therefore a characteristic property of the region (Burton, 1990).

- The most probable magnitude

The most expected extreme magnitude of a $T$-year interval is the one where the corresponding probability density is largest, i.e. $\frac{d^{2} G I I I^{T}(\omega, \mu, \lambda)}{d m^{2}}=0$ from which it follows that:

$m_{T}=\omega-(\omega-\mu)[(1-\lambda) / T]^{\lambda}$

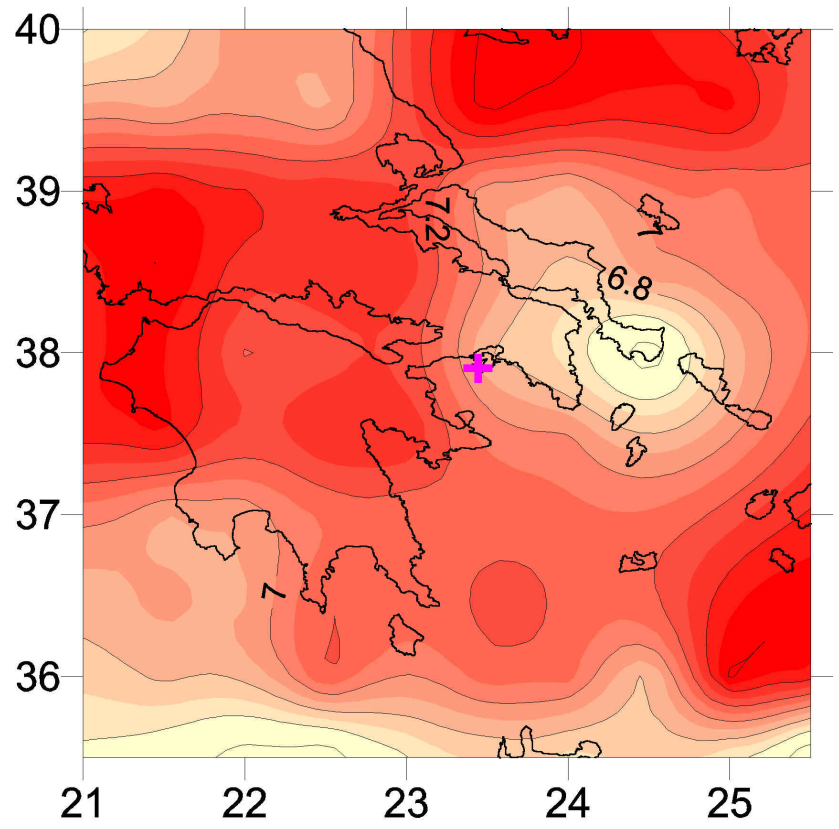

Fig. 3. The magnitude with $90 \%$ probability of not being exceeded (pnbe, 1 in 10 chance of being exceeded) over the time period of 50 years for the Revithoussa working area.

and the earthquake with probability $P$ of being a maximum or not being exceeded in a T-year interval can be obtained from Eq. (5) as:

$m_{T}(P)=\omega-(\omega-\mu)[(-\ln P) / T]^{\lambda}$.

The magnitude error $\sigma_{m}$, however, can be estimated from the following equation:

$$
\begin{aligned}
& \sigma_{m}^{2}= \sigma_{\omega}^{2}\left(\frac{\partial M}{\partial \omega}\right)^{2}+\sigma_{\mu}^{2}\left(\frac{\partial M}{\partial \mu}\right)^{2}+ \\
& \sigma_{\lambda}^{2}\left(\frac{\partial M}{\partial \lambda}\right)^{2}+2 \sigma_{\omega \mu}^{2}\left(\frac{\partial M}{\partial \omega}\right)+\left(\frac{\partial M}{\partial \mu}\right)+\ldots
\end{aligned}
$$

where $\frac{\partial M}{\partial \omega}, \frac{\partial M}{\partial \mu}$ and $\frac{\partial M}{\partial \lambda}$ are the partial derivatives of Eq. (1), and $\sigma_{\omega}, \sigma_{\mu}$ and $\sigma_{\lambda}$ the square root of the diagonal elements of the covariance matrix (Burton, 1979; Burton and Makropoulos, 1985; Makropoulos and Burton, 1985a).

\subsection{Analysis}

The study for extreme earthquake magnitudes is carried out using two-degree cells with half-degree overlap strategy to scan the region of Greece. The maps of results for the Revithoussa working area are focused results stemming from a much more general analysis for Greece (Burton et al., 2003a) and are examined here in detailed resolution. The main results are as follows. 
Table 1. Main parameters estimated to characterize the seismicity and hazard: the 50-year magnitude and at the $90 \%$ pnbe level, $\mathrm{M}_{50}$ and $\mathrm{M}_{\mathrm{P50}}$, and the most perceptible earthquakes at intensities VI, VII and VIII with magnitudes $\mathrm{M}_{\mathrm{VI}}$, $\mathrm{M}_{\mathrm{VII}}$ and $\mathrm{M}_{\mathrm{VIII}}$, for all Shield seismic alert stations of Revithoussa

\begin{tabular}{lccccccc}
\hline & LAT & LON & $\mathrm{M}_{50}$ & $\mathrm{M}_{\mathrm{p} 50}$ & $\mathrm{M}_{\mathrm{VI}}$ & $\mathrm{M}_{\mathrm{VII}}$ & $\mathrm{M}_{\mathrm{VIII}}$ \\
\hline Station 0 & 37.961 & 23.404 & 6.5 & 6.9 & 5.8 & 6.1 & 6.4 \\
Station 1 & 38.598 & 23.019 & 6.9 & 7.3 & 6.1 & 6.3 & 6.6 \\
Station 2 & 38.402 & 22.734 & 6.8 & 7.3 & 6.0 & 6.2 & 6.6 \\
Station 3 & 37.805 & 22.694 & 6.8 & 7.3 & 5.9 & 6.2 & 6.6 \\
Station 4 & 37.866 & 22.969 & 6.7 & 7.3 & 5.9 & 6.2 & 6.6 \\
Station 5 & 37.366 & 23.188 & 6.7 & 7.2 & 6.2 & 6.4 & 6.7 \\
Station 6 & 38.171 & 24.031 & 6.4 & 6.9 & 6.0 & 6.2 & 6.4 \\
Station 7 & 38.244 & 23.344 & 6.6 & 7.1 & 5.8 & 6.1 & 6.5 \\
Station 8 & 37.667 & 24.067 & 6.5 & 6.8 & 6.2 & 6.3 & 6.5 \\
\hline
\end{tabular}

Firstly, the distribution of the largest magnitude $\mathrm{M}_{50}$ (Eq. 9, Fig. 2) expected over the time period of 50 years for the working area is roughly in the range 6.6-6.8 $\mathrm{M}_{50}$ for the Revithoussa site is about 6.5 and the values for PeloponnisosHellenic zone are around 6.6. This should be the key place to be monitored by the Shield system. The zone of $\mathrm{M}_{50} \approx 7.0$ is at the northeastern part of the working area, which is to the east of Volos. This zone is far from the Revithoussa site although the value is high. However it should still be of note for the Shield system. The zone with low value $\mathrm{M}_{50} \approx 6.4$ is close to the Gulf of Petalion which is to the east of the Revithoussa site.

Secondly, the values of the magnitude $\mathrm{M}_{\mathrm{p} 50}$ (Eq. 10, Fig. 3) expected with a non-exceedance probability of $90 \%$ over the time period of 50 years for the Gulf of Corinth are in the range $\sim 7.2-7.4$. This zone is again close to Revithoussa site and therefore it should be the main zone to be monitored. $\mathrm{M}_{\mathrm{p} 50}$ for the site is about 6.8. The zones with $\mathrm{M}_{\mathrm{p} 50} \geq 7.4$ are: (a) the region to the west of Patras and (b) that to the northeast of Volos. The first of these is not far from the site and it is of great importance for the Shield. The low value $\mathrm{M}_{\mathrm{p} 50} \leq 6.8$ is for the Gulf of Petalion in the east.

Results for earthquake perceptibility are shown as Figs. 4a-c. These also provide reference hazard parameters for the Shield early warning monitoring system; the most perceptible earthquake indicating the magnitude of the earthquake that is most likely to be felt at a specific level of intensity. The main results are as follows.

Firstly, the values of most perceptible earthquake magnitude $\mathrm{M}_{\mathrm{VI}}$ (Eq. 8, Fig. 4a) for intensity VI in the Gulf of Corinth are approximately 5.8-6.0. This zone is close to the Revithoussa site. There is $\mathrm{M}_{\mathrm{VI}} \approx 5.8$ for the site. $\mathrm{M}_{\mathrm{VI}} \geq 6.8$ is for the locality to the northeast of Skiros. The values for most other localities are in the range 6.2-6.6. Secondly, the value $\mathrm{M}_{\mathrm{VII}}$ (Fig. 4b) for intensity VII at the site is 6.1 . The values for the Gulf of Corinth and the neighboring region near Revithoussa are approximately 6.2-6.4. The high value $\mathrm{M}_{\mathrm{VII}} \geq 7.0$ is for the locality near Limnos in the northeastern part of the working area. The values for most other localities are 6.4-6.8. Thirdly, the value MVIII (Fig. 4c) for intensity VIII at the site is about 6.4. The values of $\mathrm{M}_{\mathrm{VIII}}$ for the Gulf of Corinth and the neighboring region near Revithoussa are approximately 6.4-6.6. The place with high value $\mathrm{M}_{\text {VIII }} \geq 7.1$ is near Limnos. The values for other localities in the working area are in the range 6.6-6.8.

The main parameters estimated to characterize the seismicity and hazard are: the 50-year magnitude and the same with $90 \%$ pnbe (one in 10 chance of being exceeded), $\mathrm{M}_{50}$ and $\mathrm{M}_{\mathrm{p} 50}$, and the most perceptible earthquakes at intensities VI, VII and VIII with magnitudes $\mathrm{M}_{\mathrm{VI}}, \mathrm{M}_{\mathrm{VII}}$ and $\mathrm{M}_{\mathrm{VIII}}$. These parameters for all Shield seismic alert stations of Revithoussa (Fig. 1) are shown in Table 1. These are the important references characterizing seismicity for the stations.

\section{Regional strong ground acceleration hazard for Re- vithoussa based on free-zonation}

\subsection{Method}

\subsubsection{Gumbel's 1st distribution for annual maximum accel- eration}

Similar to the discussion in Sect. 3.1, we also use the extreme value distribution of Gumbel (1966) for this study. Here the first Gumbel asymptotic distribution (Gumbel I) is given by

$G^{I}(a)=\exp \{-\exp [-\alpha(a-u)]\}$

where $\alpha$ and the characteristic modal extreme $u$ are two parameters of this distribution, and $G^{I}$ is the probability that $a$ is an annual extreme of peak ground acceleration at a point.

The peak ground acceleration expected to be the annual maximum with probability $P$ is given by

$a_{P}=u-[\ln (-\ln P)] / \alpha$

or the peak ground acceleration which has probability $P$ of not being exceeded in $T$ year is

$a_{P, T}=u-[\ln (-\ln P)] / \alpha+(\ln T) / \alpha=a_{P}+(\ln T) / \alpha$ 

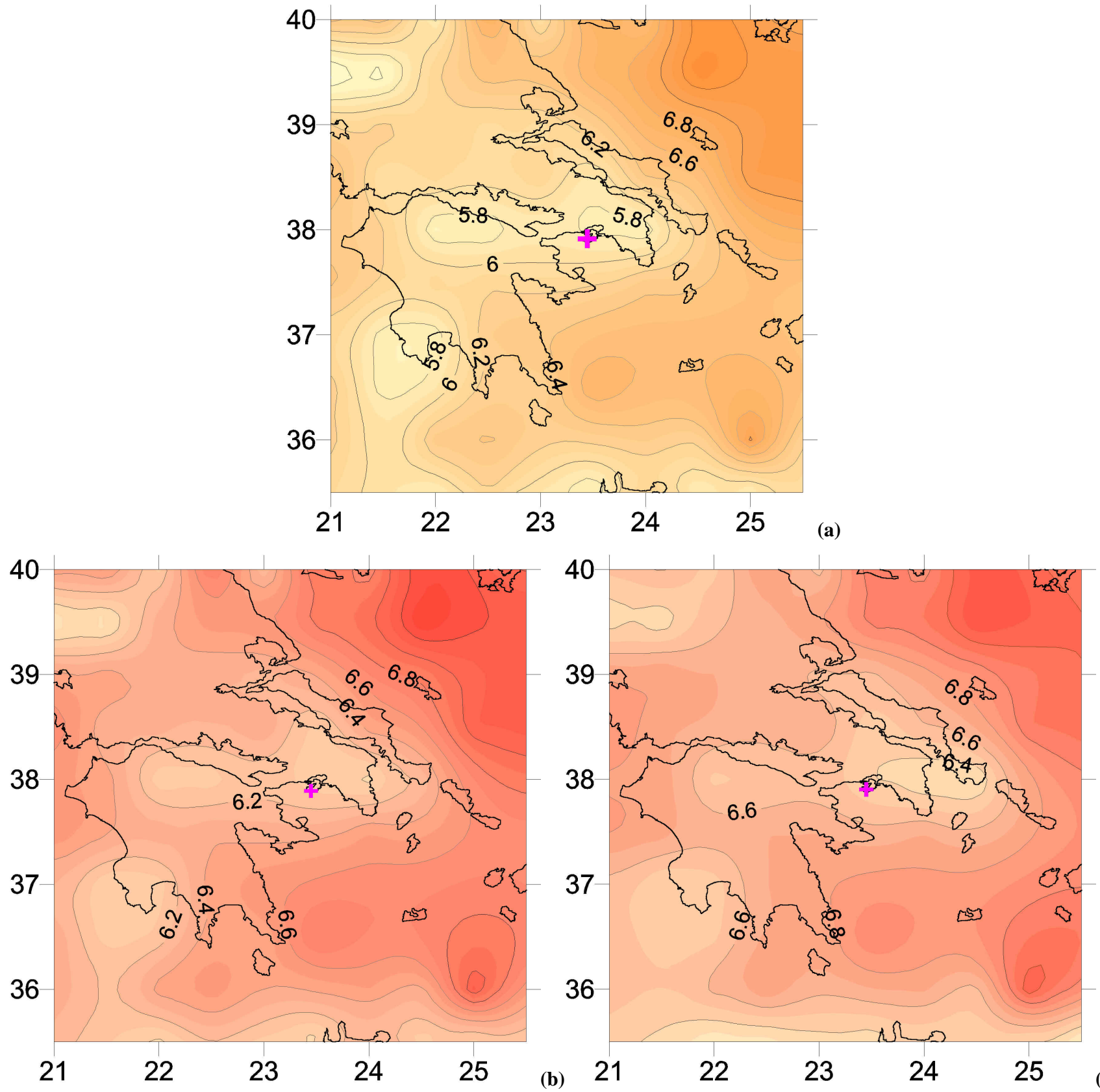

Fig. 4. The most perceptible earthquake magnitude for intensities (a) VI, (b) VII and (c) VIII, respectively for the Revithoussa working area.

This paper does not use Gumbel's 3rd distribution for the annual maximum acceleration as this will result in poor convergence with value of curvature $\lambda$ close to zero (Makropoulos and Burton, 1985b), because maximum accelerations are not physically analogous to maximum magnitudes.

\subsubsection{Peak ground acceleration attenuation model}

- MB Peak Ground Acceleration Model

Makropoulos and Burton (1985b) derived a peak acceleration attenuation model from eight well known formulae which resulted from worldwide studies because the limited numbers of strong motion records did not permit regional study of attenuation of ground vibration in Greece at that time. This model or formula is given by

$a=2164 e^{0.7 M s}(r+20)^{-1.80}$

where $a$ is peak ground acceleration, $\mathrm{M}_{\mathrm{S}}$ is earthquake magnitude and $r$ is hypocentral distance in kilometers. This attenuation law is an average of eight independent attenuation laws used to describe the attenuation of peak ground acceleration by various authors in the mid-1970s 
(Ahorner and Rosenhaur, 1975; Bath, 1975; Donovan, 1973; Katayama, 1974; Orphal and Lahoud, 1974; Shah and Movassate, 1975; Trifunac, 1976). This average law was demonstrably compatible with the few observations of strong ground motion then available.

- TP Peak Ground Acceleration Model

This TP model (Theodulidis and Papazachos, 1992) was obtained directly using 105 horizontal records from 36 shallow earthquakes in Greece, with magnitudes 4.5-7.0, (plus a further 16 horizontal components from four shallow subduction earthquakes in Japan and Alaska, 7.2-7.5 M):

$$
\begin{aligned}
& \ln \left(a_{h}\right)=3.88+1.12 M_{S}- \\
& 1.65 \ln (R+15)+0.41 S+0.7 P
\end{aligned}
$$

where $a_{h}$ is the peak horizontal acceleration in $\mathrm{cm} \mathrm{s}^{-2}$, $R$ is epicentral distance in $\mathrm{km}, S$ is equal to zero at "alluvium" sites and equal to one at a "rock" site, and $P$ is zero for mean or 50-percentile values and one for 84percentile values.

\section{- NTP Peak Ground Acceleration Mode}

Theodulidis (2001) pointed out that there are some problems about Eq. (16) when selecting $S=1$ at a "rock" site. This is because the majority of strong motion data, which they had at that time recorded on "rock" and used in their regression analysis, came from a station whose surface geology was characterized as "rock". In fact, the later geotechnical investigation on site found a thin layer $(\sim 10 \mathrm{~m})$ of weathered material that amplified strong motion around 5-7 Hz. Therefore PGA was observed in this frequency range. The soil category "rock" is slightly biased by this site and this attenuation relation for "rock" may be absolutely valid only for similar soil/depth properties. However, peak ground velocity and displacement were not affected by this thin layer because these anomalies usually appear at the lower frequencies. Theodulidis suggests that $S=0.5$ should be used for "stiff soil" condition instead of $S=1$ for "rock". This corrected TP model is referred to as the NTP model.

- Ambraseys Peak Ground Acceleration Model Ambraseys (1997) in a European Commission SRD document supplies the equation for horizontal accelerations:

$$
\begin{aligned}
& \log \left(a_{h}\right)=-1.242+0.238 M_{S}- \\
& 0.00005 r-0.907 \log (r)+0.240 P
\end{aligned}
$$

$\log \left(a_{h}\right)=-0.895+0.215 M_{S}-$

$$
0.00011 r-1.070 \log (r)+0.247 P .
$$

Equation (17a) is calculated with no depth control in $\mathrm{M}_{\mathrm{S}}$ magnitude range 5.0-7.3. $h_{o}$ is 4.04 in $r^{2}=d^{2}+h_{o}^{2}$ in Eq. (17a). Equation (17b) is calculated with depth control using $r^{2}=d^{2}+h^{2}(r$ is slant distance to the source using focal depth $h$; there is no $h_{o}$ ) and in $\mathrm{M}_{\mathrm{S}}$ magnitude range 5.0-7.3. Equations (17a) and (17b) may be appropriate to analyze horizontal PGA seismic hazard by our extreme value approach, since magnitudes $<5 \mathrm{M}_{\mathrm{S}}$ are unlikely to cause damage and be of engineering concern (Burton et al., 2003b).

- Comparisons for the Suite of Attenuation Relationships with Distance

We adopt 50-percentile curves for attenuation relations because it would preclude comparison of ensuing results with values in the NEAK (New Greek Seismic Resistant Code, 1992) map if 84-percentile high values were used. Figures $5 \mathrm{a}$ and $\mathrm{b}$ show the peak ground acceleration as a function of distance for a nominal earthquake of magnitude $6.5 \mathrm{M}_{\mathrm{S}}$ at focal depths $h=10 \mathrm{~km}$ and $h=0 \mathrm{~km}$ respectively. In other words, we use ah_tp, ah_ntp, ah_am1, ah_am2 and ah_mb respectively from Eqs. (16), NTP model, (17a) and (17b) for 50 percentile values and for "rock" sites, and 15 for this study. These five curves are shown in Figs. 5a-b under the different depth conditions.

The curves ah_tp and ah_ntp obtained directly from Greek data are quite similar to the curve ah_mb derived from other areas outside Greece, while the curve ah_am1 derived from European data without depth control is close to ah_am2 derived from European data without depth control. The PGA values represented by the curves ah_tp and ah_mb are quite similar to the corresponding values in the NEAK map, but those represented by the curves ah_am 1 and ah_am 2 are much smaller than those in the NEAK map. It seems that the Eqs. (15), (16) and NTP model are most appropriate to analyze horizontal PGA seismic hazard by our extreme value approach and further equations are being developed by others (Margaris et al., 2002).

4.2 Estimations of regional ground acceleration hazard of Revithoussa

\subsection{1 $\quad$ MB model}

The Greek region is divided into a grid of mesh $0.5^{\circ}$ intervals of latitude and longitude. All earthquakes above the magnitude threshold are selected within two degrees of each grid point to calculate PGA at the grid point based on the MB model and the Gumbel I distribution fitted to the ranked annual extreme PGA values. This paper uses $0.5^{\circ}$ meshes as the base for all attenuation models.

Figure 6 shows the result based on the MB model with $90 \%$ probability of not being exceeded during the time period $T=50$ years for data $1900-1999, \mathrm{M}_{\mathrm{S}} \geq 5.5$. There are two regions with high PGA values $\left(\geq 200 \mathrm{~cm} \mathrm{~s}^{-2}\right.$ ). These are the 

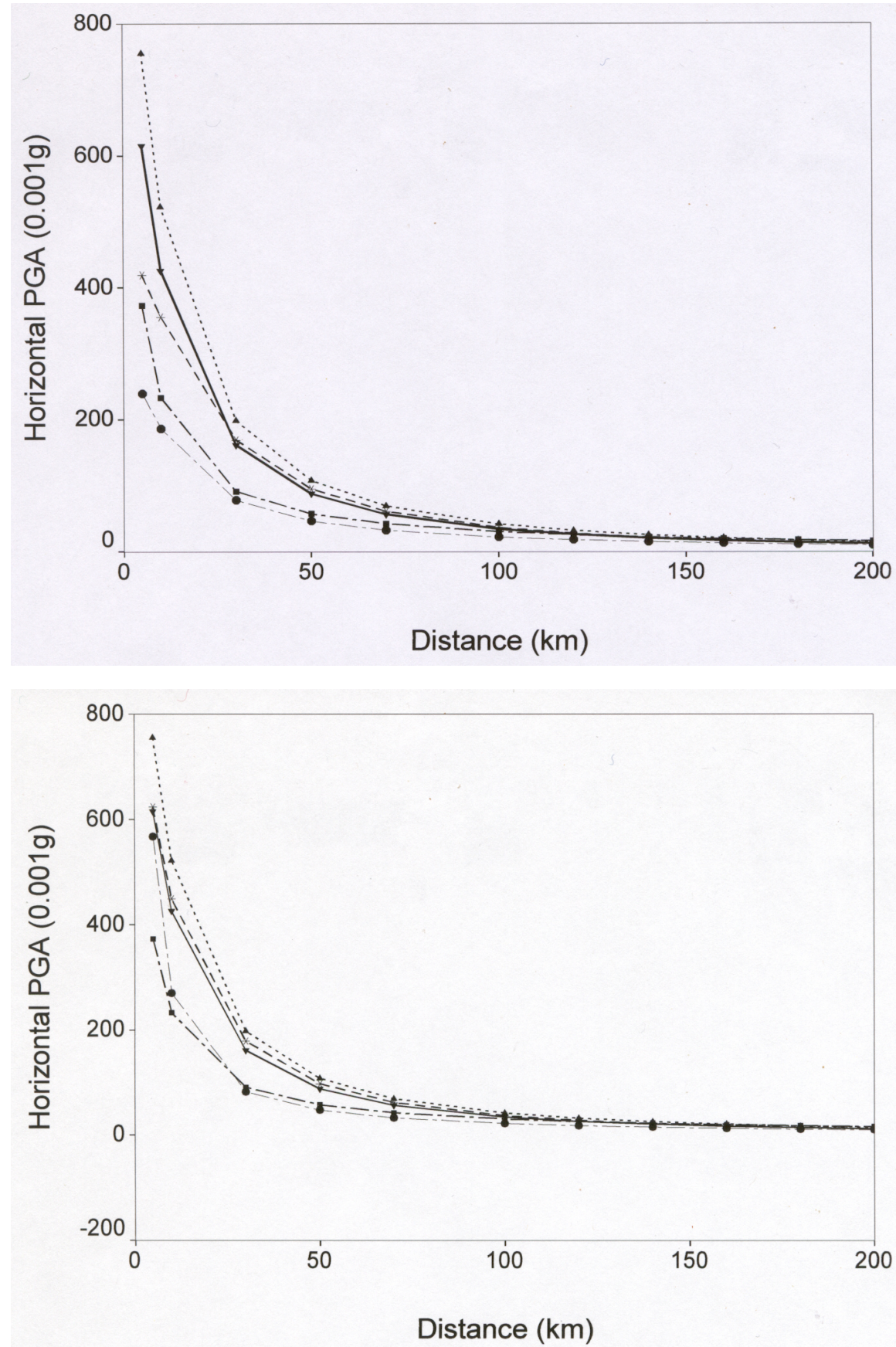

Fig. 5. (a) The attenuation relations used in the seismic hazard evaluation in Greece for a nominal earthquake of magnitude $6.5 \mathrm{M}_{\mathrm{S}}$ at focal depth $h=10 \mathrm{~km}$. The key for the curves is as follows: Ah_tp $(\boldsymbol{\Delta})$ and ah_ntp ( $\mathbf{\nabla})$ are respectively for Eq. (16) and NTP model (stiff soil sites) for 50-percentile values. ah_am1 (ם), ah_am2 (•) and ah_mb (*) are respectively for the Eqs. (17a) and (17b) for 50-percentile values and for "rock" sites, and for Eq. (15); (b) as same as (a) except at focal depth $h=0.0 \mathrm{~km}$.

Gulf of Corinth, and Limnos Island and neighboring regions northeast from Revithoussa. The region east and southeast from Revithoussa has low PGA values. The distribution for data 1964-1999 $\left(\mathrm{M}_{\mathrm{S}} \geq 4\right.$ 4.0) has similar results. The PGA value based on the MB model with $90 \%$ probability of not being exceeded during the time period $T=50$ years for data $1900-1999\left(\mathrm{M}_{\mathrm{S}} \geq 5.5\right)$ is about $186 \mathrm{~cm} \mathrm{~s}^{-2}$ for Revithoussa (Table 2). NTP, AM1 and AM2 models at Revithoussa.

\subsubsection{TP model}

Figure 7 shows the results based on TP model with $90 \%$ probability of not being exceeded during the time period $T=50$ years (50-percentile, rock sites) for data 1900$1999\left(\mathrm{M}_{\mathrm{S}} \geq 5.5\right)$ : there are three main regions with high PGA values $\geq 300 \mathrm{~cm} \mathrm{~s}^{-2}$. These are the Gulf of Corinth, the region south from Peloponnisos (the southeastern part 
of the Helenic arc seismic zone) and Limnos Island and the neighboring region northeast from Revithoussa. However the region east from Revithoussa has low PGA values. From the distribution for data $1964-1999\left(\mathrm{M}_{\mathrm{S}} \geq 4\right.$ 4.0) there are two main regions with high PGA values $\geq 300 \mathrm{~cm} \mathrm{~s}^{-2}$ : the Gulf of Corinth and the northeastern part of this working area. However, in this case the Peloponnisos is not a region with high values because the time period for this set of data does not include the strong earthquakes before 1964 . The PGA value based on the TP model with $90 \%$ probability of not being exceeded during the time period $T=50$ years (50-percentile, rock sites) for data $1900-1999\left(\mathrm{M}_{\mathrm{S}} \geq 5.5\right)$ is about $249 \mathrm{~cm} \mathrm{~s}^{-2}$ for Revithoussa (Table 2).

\subsubsection{NTP model}

From Fig. 8 based on the NTP model with $90 \%$ probability of not being exceeded during the time period $T=50$ years (50-percentile, rock sites) for data 1900-1999 ( $\mathrm{M}_{\mathrm{S}} \geq 5.5$ ), there are three regions with high PGA values $\left(\geq 250 \mathrm{~cm} \mathrm{~s}^{-2}\right)$. These are the Gulf of Corinth, the region south from the Peloponnisos (that is the Hellenic seismic zone from the southern and southwestern coast of Peloponnisos to Crete along the Hellenic trench or arc), and the Limnos Island region northeast from Revithoussa. The region east from Revithoussa still shows low PGA values. The PGA values based on the NTP model are smaller than those for the TP model and these seem to be more reasonable. This distribution based on NTP model is quite similar to that from the TP model (Fig. 9). As discussed in Sect. 4.1.2, NTP model is derived from the TP model with some corrections. Therefore the PGA distributions based on the NTP model should be more reasonable. The results based on the TP model show larger values which are very different from the results based on either the MB model or NEAK. The NTP model is derived directly from Greek data. It should correctly reflect the distribution of the expected strong motion for the Revithoussa working area in Greece. The distribution for data $1964-1999\left(\mathrm{M}_{\mathrm{S}} \geq 4.0\right)$ is similar to that in Fig. 8. The reason it does not reflect the distribution with high value in the Peloponnisos is as described in Sect. 4.2.2. The PGA value based on the NTP model with $90 \%$ probability of not being exceeded during the time period $T=50$ years (50-percentile, stiff soil sites) for data $1900-1999\left(M_{\mathrm{S}} \geq 5.5\right)$ is about $203 \mathrm{~cm} \mathrm{~s}^{-2}$ for Revithoussa (Table 2).

\subsubsection{Ambraseys models}

In the distribution of PGA values based on Ambraseys model (no depth control) with $90 \%$ probability of not being exceeded during the time period $T=50$ years (50-percentile, rock sites, Eq. (17a) for data 1900-1999 (M $\geq$ 5.5)) (Fig. 9), we can still find three regions with PGA values $\geq 150 \mathrm{~cm} \mathrm{~s}^{-2}$. These are the Gulf of Corinth, Limnos Island and the neighboring region and the region southeast from Peloponnisos. However the values based on Ambraseys model are small compared with the corresponding values

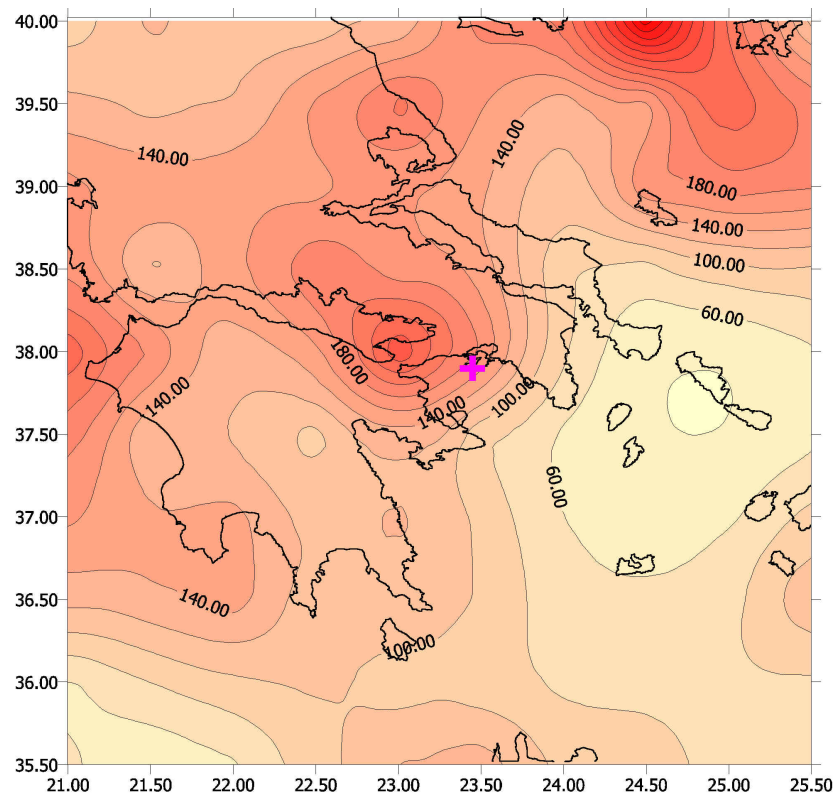

Fig. 6. Contour map of expected maximum peak ground acceleration $\left(\mathrm{cm} \mathrm{s}^{-2}\right)$ with $90 \%$ pnbe during 50 years for the Shield regional working area of Revithoussa: MB model (Data: 1900-1999, $\mathrm{M}_{\mathrm{S}} \geq 5.5$; see Eq. (15)).

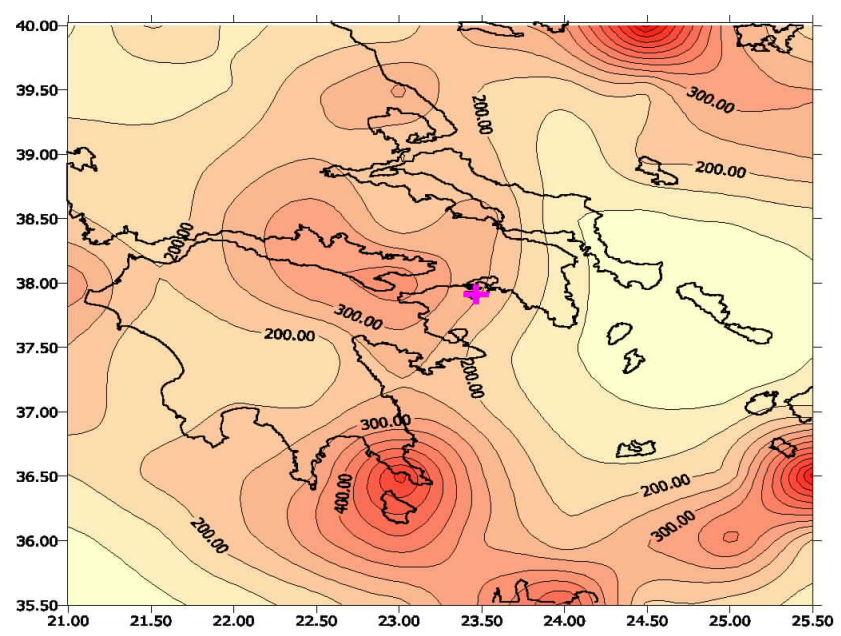

Fig. 7. Contour map of expected maximum peak ground acceleration $\left(\mathrm{cm} \mathrm{s}^{-2}\right)$ with $90 \%$ pnbe during 50 years for the Shield regional working area of Revithoussa: TP model (Data: 1900-1999, $\mathrm{M}_{\mathrm{S}} \geq$ 5.5; see Eq. (16), 50-percentile, rock sites).

based on MB, TP or NTP models. This deviates from the reality of seismicity related to strong ground shaking in Greece, and although this model may represent the global acceleration relation based on the European database, the seismicity in Greece requires specific study. The results for data 1964$1999\left(\mathrm{M}_{\mathrm{S}} \geq 4.0\right)$ are also low and could not reflect the reality of seismicity in Greece. The PGA value based on this model with $90 \%$ probability of not being exceeded during the time period $T=50$ years (50-percentile, rock sites) for data $1900-1999\left(\mathrm{M}_{\mathrm{S}} \geq 5.5\right)$ is about $131 \mathrm{~cm} \mathrm{~s}^{-2}$ for Revithoussa. 
Table 2. Acceleration $\left(\mathrm{cm} \mathrm{s}^{-2}\right)$ which have $90 \%$ probability of not being exceeded in $T$ years based on the MB, TP, NTP, AM1 and AM2 models at Revithoussa

\begin{tabular}{lllllc}
\hline $\begin{array}{l}\text { Revithoussa } \\
\begin{array}{l}37.96^{\circ} \mathrm{N} \\
23.40^{\circ} \mathrm{E}\end{array}\end{array}$ & $T=25$ years & $T=50$ years & $T=100$ years & $T=200$ years & References \\
\hline & & & & & \\
\hline & 116.2 & 129.1 & 142.1 & 155.0 & MB_1 \\
& 163.3 & 185.8 & 208.3 & 230.8 & MB_2 \\
& 161.6 & 180.6 & 199.5 & 218.4 & TP_1 \\
218.4 & 248.7 & 278.9 & 309.1 & TP_2 \\
131.7 & 147.1 & 162.5 & 177.9 & NTP_1 \\
177.9 & 202.6 & 227.2 & 251.8 & NTP_2 \\
101.2 & 111.9 & 122.7 & 133.4 & AM1_1 \\
116.3 & 131.0 & 145.7 & 160.5 & AM1_2 \\
& 64.7 & 71.5 & 78.3 & 85.0 & AM2_1 \\
& 82.2 & 92.8 & 103.5 & 103.5 & AM2_2 \\
\hline
\end{tabular}

MB_1: Data $\left(\mathrm{M}_{\mathrm{S}} \geq 4.0,1964-1999\right) 90 \%$, MB Model.

MB_2: Data $\left(\mathrm{M}_{\mathrm{S}} \geq 5.5,1900-1999\right) 90 \%$. MB Model.

TP_1: Data $\left(\mathrm{M}_{\mathrm{S}} \geq 4.0,1964-1999\right)$ 90\%, TP Model, 50-percentile, rock sites.

TP_2: Data $\left(\mathrm{M}_{\mathrm{S}} \geq 5.5,1900-1999\right) 90 \%$. TP Model., 50-percentile, rock sites.

NTP_1: Data (MS $\geq 4.0,1964-1999)$ 90\%, NTP Model, 50-percentile, stiff soil sites.

NTP_2: Data ( $\left.\mathrm{M}_{\mathrm{S}} \geq 5.5,1900-1999\right)$ 90\%. NTP Model., 50-percentile, stiff soil sites.

AM1_1: Data (MS $\geq 4.0,1964-1999)$ 90\%, Ambraseys Model with no depth control, 50-percentile, rock sites.

AM1_2: Data $\left(M_{S} \geq 5.5,1900-1999\right)$ 90\%. Ambraseys Model with no depth control, 50-percentile, rock sites.

AM2_1: Data ( $\left.\mathrm{M}_{\mathrm{S}} \geq 4.0,1964-1999\right)$ 90\%, Ambraseys Model with depth control, 50-percentile, rock sites.

AM1_2: Data $\left(M_{S} \geq 5.5,1900-1999\right) 90 \%$. Ambraseys Model with depth control, 50-percentile, rock sites.

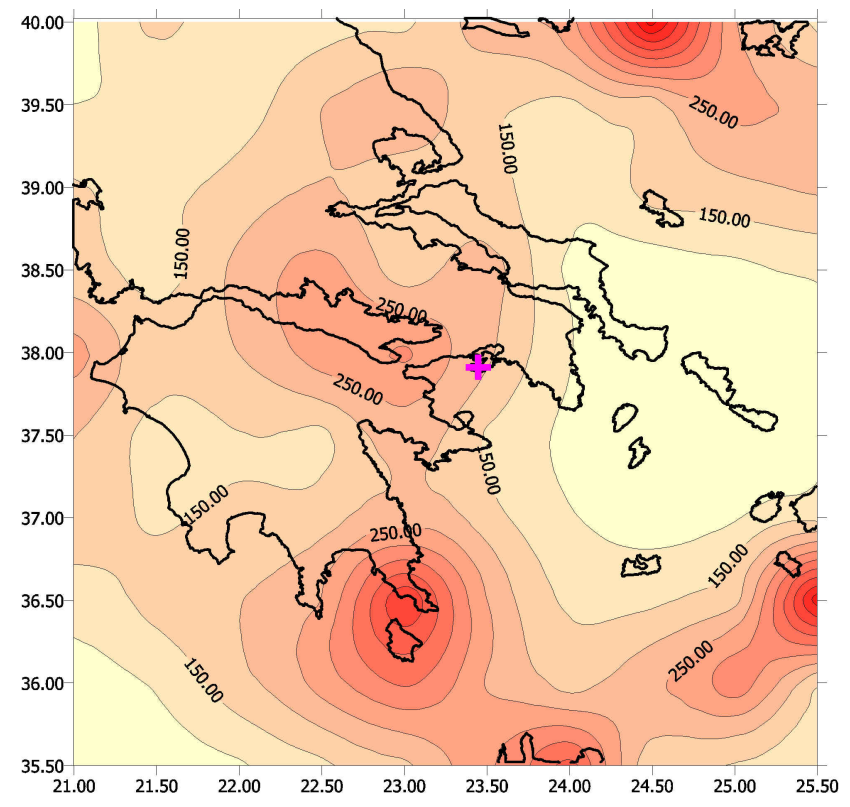

Fig. 8. Contour map of expected maximum peak ground acceleration $\left(\mathrm{cm} \mathrm{s}^{-2}\right.$ ) with $90 \%$ pnbe during 50 years for the Shield regional working area of Revithoussa: NTP model (Data: 1900-1999, $\mathrm{M}_{\mathrm{S}} \geq 5.5$; see modifications to Eq. (16), 50-percentile, rock sites).

The results based on Ambraseys model (depth control) with $90 \%$ probability of not being exceeded during the time period $T=50$ years (50-percentile, rock sites, Eq. $17 \mathrm{~b})$ for data $1900-1999\left(\mathrm{M}_{\mathrm{S}} \geq 5.5\right)$ are shown in Fig. 10. We still can see two regions with values $\geq 100 \mathrm{~cm} \mathrm{~s}^{-2}$. These are the Gulf of Corinth and Limnos Island and neighboring region. However the values are even smaller than those without depth control. The results for data 1964-1999 $\left(\mathrm{M}_{\mathrm{S}} \geq 4.0\right)$ are similar to those in Fig. 10. The PGA value based on this model with $90 \%$ probability of not being exceeded during the time period $T=50$ years (50-percentile, rock sites) for data $1900-1999\left(M_{S} \geq 5.5\right)$ is about $93 \mathrm{~cm} \mathrm{~s}^{-2}$ for Revithoussa.

\subsection{Summary}

Estimations of local ground acceleration hazard for the Shield regional working area of Revithoussa indicate that the results based on two Ambraseys models appear to give too low PGA values, deviating from the reality of seismicity related to earthquake strong ground shaking in Greece. The results based on the MB model are similar to those of NEAK. The MB law is an average of independent attenuation laws derived from other areas outside Greece. The TP and NTP models (Theodulidis and Papazachos, 1992; Theodulidis, 2001) directly drew on 105 Greek historical records of earthquake strong ground shaking, and should be reasonable for the seismicity in Greece. The results based on TP model may be higher than NEAK, while the results based on NTP model are similar to those of NEAK. It is clear that NTP 
Table 3. Acceleration $\left(\mathrm{cm} \mathrm{s}^{-2}\right)$ which have $90 \%$ probability of not being exceeded in 50 years based on the MB, TP, NTP, AM1 and AM2 models for all Shield seismic alert stations of Revithoussa (Data 1900-1999, $\mathbf{M}_{\mathbf{S}} \geq 5.5$ )

\begin{tabular}{lrrrrrrr}
\hline & LAT & LON & NTP & TP & MB & AM1 & AM2 \\
\hline Station 0 & 37.961 & 23.404 & 202.6 & 248.6 & 185.8 & 131.0 & 92.8 \\
Station 1 & 38.598 & 23.019 & 138.7 & 192.7 & 166.8 & 114.2 & 88.0 \\
Station 2 & 38.401 & 22.734 & 220.6 & 307.6 & 217.4 & 150.1 & 109.2 \\
Station 3 & 37.805 & 22.694 & 196.7 & 274.4 & 131.6 & 97.1 & 66.4 \\
Station 4 & 37.866 & 22.969 & 264.9 & 371.1 & 184.9 & 174.1 & 91.1 \\
Station 5 & 37.366 & 23.188 & 196.9 & 277.2 & 102.8 & 143.6 & 55.3 \\
Station 6 & 38.171 & 24.031 & 87.2 & 121.4 & 88.3 & 75.6 & 48.2 \\
Station 7 & 38.244 & 23.344 & 274.2 & 336.6 & 268.6 & 232.2 & 153.3 \\
Station 8 & 37.667 & 24.067 & 71.1 & 99.0 & 57.5 & 56.1 & 33.8 \\
\hline
\end{tabular}

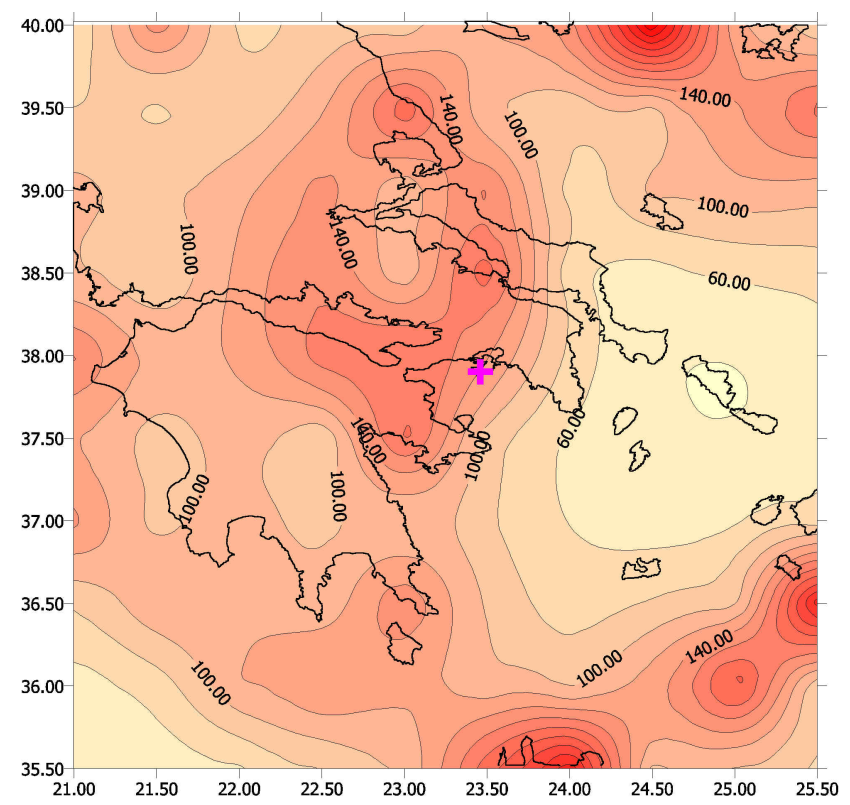

Fig. 9. Contour map of expected maximum peak ground acceleration $\left(\mathrm{cm} \mathrm{s}^{-2}\right.$ ) with $90 \%$ pnbe during 50 years for the Shield regional working area of Revithoussa: Ambraseys model without depth control (Data: 1900-1999, $\mathrm{M}_{\mathrm{S}} \geq$ 5.5; See Eq. (17a), 50-percentile, rock sites).

model (Theodulidis, 2001) corrects the TP model (Theodulidis and Papazachos, 1992) and therefore it reflects the reality of seismicity in Greece. According to NTP model, NEAK values may need to increase slightly to be in complete harmony. This result is supported by other results such as assessments of earthquake hazard in Turkey and its neighboring region by Erdik et al. (1999).

In spite of the above small differences, all analyses show in common that, within the Shield region, the most important zone to be monitored is WNW from Revithoussa, the Shield centre and is at a relatively short distance $(50 \mathrm{~km}$ or less), the Gulf of Corinth (active normal faults) region. This is the critical zone for early warning. A second key region of seismicity is at an intermediate distance $(100 \mathrm{~km}$ or more)

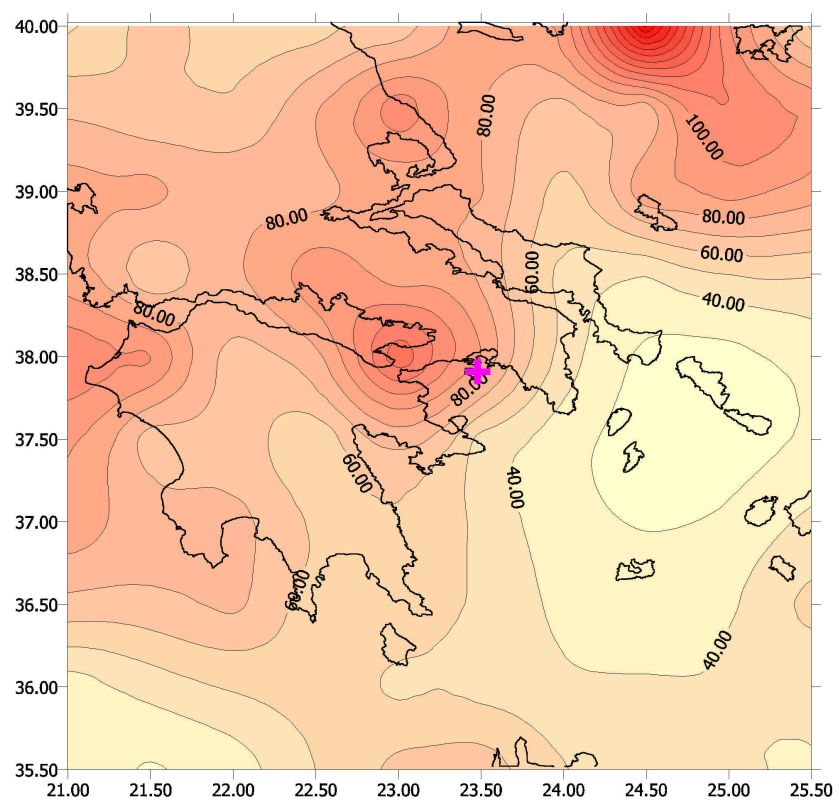

Fig. 10. Contour map of expected maximum peak ground acceleration $\left(\mathrm{cm} \mathrm{s}^{-2}\right)$ with $90 \%$ pnbe during 50 years for the Shield regional working area of Revithoussa: Ambraseys model with depth control (Data: 1900-1999, $\mathrm{M}_{\mathrm{S}} \geq$ 5.5; See Eq. (17b), 50-percentile, rock sites).

from the centre, the Hellenic seismic zone south or southeast from Peloponnisos. A third region to be detected would be the north-eastern region from the centre and is at a relatively long distance (about $150 \mathrm{~km}$ ), Lemnos Island and neighboring region in the area influenced by the western extensions of the North Anatolian Fault zone. The eastern region from this centre is a region with low expected PGA values. This is not the key region for seismic detection although attention is necessary to avoid false alarms. PGA values at the Revithoussa site for different models and datasets are summarized in Table 2. Among these, the PGA value based on NTP model with $90 \%$ probability of not being exceeded during the time period $T=50$ years (50-percentile, stiff soil sites) for data $1900-1999\left(\mathrm{M}_{\mathrm{S}} \geq 5.5\right)$ is about $203 \mathrm{~cm} \mathrm{~s}^{-2}$. 


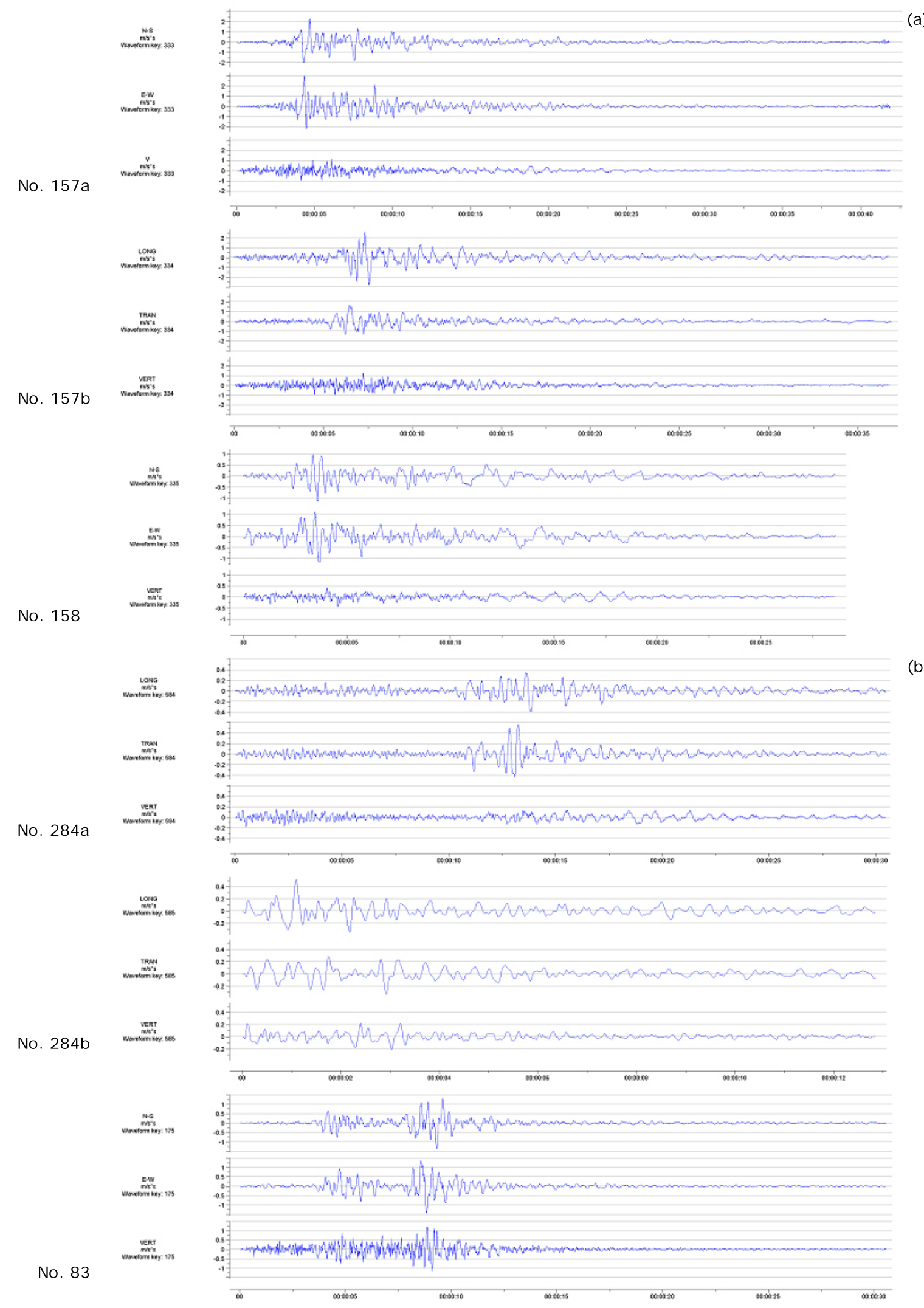

Fig. 11. (a-d) Scenario or Alert Signals (earthquake strong-motion accelerograms) for Revithoussa, Shield Centre. (See numbers as in Table 4 (a), (b). 


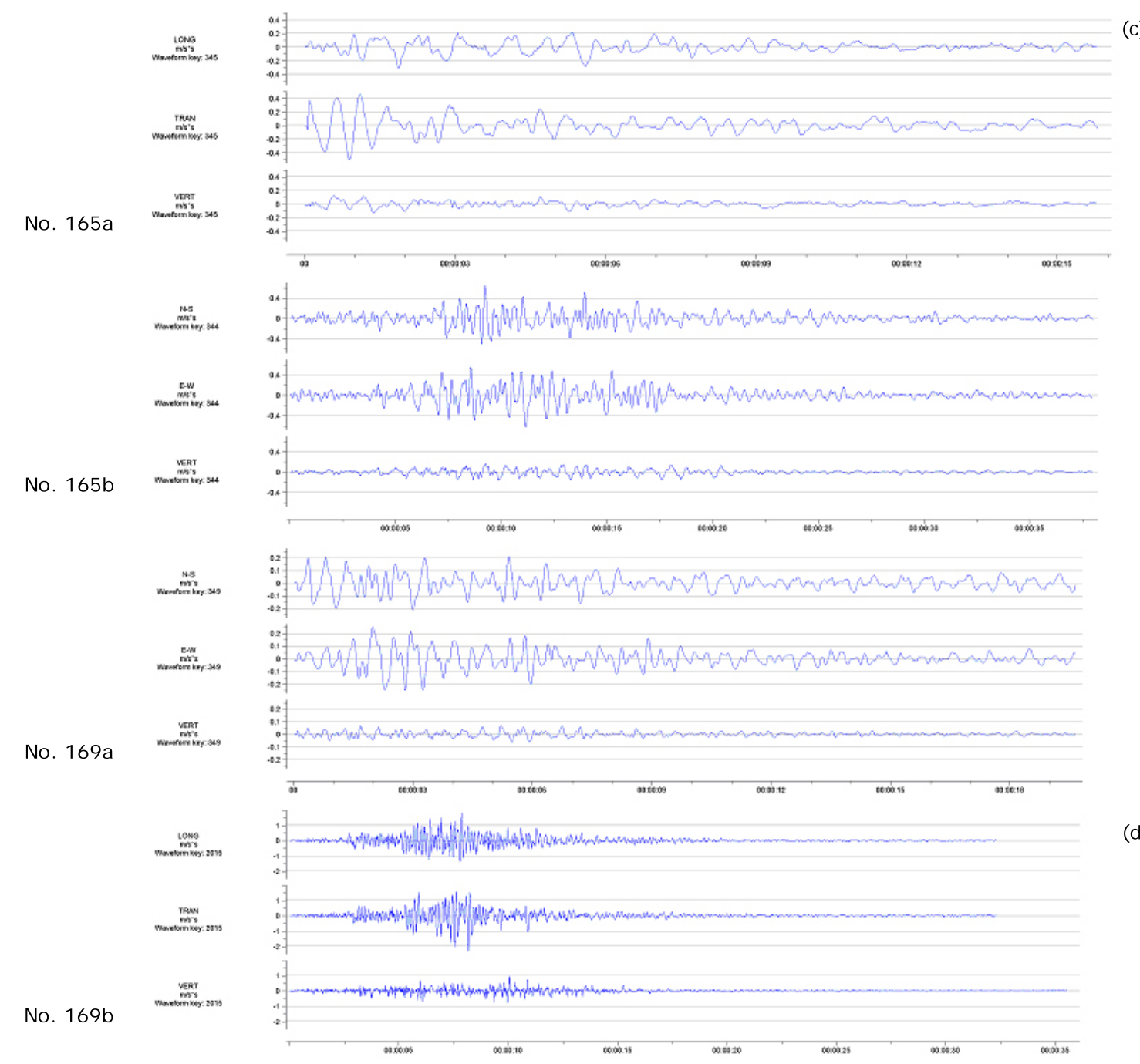

(c)

Fig. 11. continued ...

This value should be accepted as a typical estimation of local ground acceleration hazard of this earthquake early warning Shield. Here accelerations $\left(\mathrm{cm} \mathrm{s}^{-2}\right)$ which have $90 \%$ probability of not being exceeded in 50 years based on the MB, TP, NTP, AM1 and AM2 models for all Shield seismic alert stations (Fig. 1a) of the early warning network are also listed in Table 3. These provide key references for expected levels of strong ground shaking at these stations and can be considered as alert-level strength.

In short, the above results provide the background to design earthquake monitoring stations for this system to supply an effective early warning Shield for Revithoussa hydrocarbon centre. These data enable the selection of expected alertsignals i.e. examples of strong ground vibration histories that might be expected at these Shield stations.

It must be stressed that average attenuation models have been used here because the aim of this paper is to provide the general estimation of local seismic hazard in the regional working area of Revithoussa by studying extremes of PGA.
It is well known that individual source-site azimuths may deviate from such averages. Uncertainties introduced by the influence of the local ground condition at the sites may also need to be taken specifically into account. PGA alone may not be a sufficient basis for developing critical alarm parameters and the frequency content and the duration of signals may also prove important in the decision making process, never-the-less PGA quantifies the regional seismic hazard through a well understood parameter.

\section{Selection of strong motion signals for alert}

Design of the Shield earthquake early warning stations can be regarded as the search for assumed earthquakes that represent all characteristics and behaviours of the earthquakes likely to be experienced within 50 years at each station. Therefore the task for this section should combine with earthquake scenario selection based on Sects. 3-4 to identify the type of strong 
motion signals for which stations in the early warning Shield network should be on the alert.

As discussed in Sects. 3-4, accelerations which have 90\% probability of not being exceeded in 50 years based on different attenuation models for all Shield seismic alert stations are listed in Table 3. Also the main parameters estimated to characterize the seismicity and hazard: the 50-year magnitude and at the $90 \%$ pnbe, $\mathrm{M}_{50}$ and $\mathrm{M}_{\mathrm{P} 50}$, and the most perceptible earthquakes at intensities VI, VII and VIII with magnitudes $\mathrm{M}_{\mathrm{VI}}, \mathrm{M}_{\mathrm{VII}}$ and $\mathrm{M}_{\mathrm{VIII}}$ for all stations are shown in Table 1. These can be used in the selection of earthquake strong motion data, which might rarely be monitored - perceived - at each station. These are termed "alert signals".

The extreme magnitude values such as $\mathrm{M}_{50}$ and $\mathrm{M}_{\mathrm{P} 50}$ (Table 1) are the criteria used to select the characteristic events. The CD-ROM of the European strong-motion databank (Ambraseys et al., 2000) supplies a database for the selections. Here we have two principles. The first is idealism. This means that the maximum values in Table 1 should be used as criteria for selection for the station if possible. The second is practical. This means that the database should be used fully for the selections if reasonable. In practice, a balance between both principles is maintained to ascertain likely repeatable average peak acceleration in a future event.

As shown in Table 1, the range for $\mathrm{M}_{\mathrm{P} 50}$ is $6.8-7.3 \mathrm{M}_{\mathrm{S}}$. Variation of \pm 0.5 is accepted on magnitude when considering the errors and other factors. Then the range becomes $6.8 \pm 0.5-7.3 \pm 0.5 \mathrm{M}_{\mathrm{S}}$. If $\mathrm{M}_{\mathrm{P} 50}$ is accepted as the criterion, then a small number of historical strong motion records or signals are selected because the maximum record for Greece in the databank of European accelerograms is $7.02 \mathrm{M}_{\mathrm{S}}$. However the range for $\mathrm{M}_{50}$ is $6.4-6.9 \mathrm{M}_{50}$. With variation of \pm 0.5 on magnitude, the range becomes $6.4 \pm 0.5-6.9 \pm 0.5 \mathrm{M}_{\mathrm{S}}$ using $\mathrm{M}_{50}$ as the criterion. There are two advantages. First, there is a considerable number of historical strong motion records or signals now available for selection. In this way the database can be used effectively. Secondly, this selection will contain some of those from the previous selection, which used $\mathrm{M}_{\mathrm{P} 50}$ as the criterion. $\mathrm{M}_{50}$ is used herein as a principal criterion with variation of \pm 0.5 on magnitude.

For example, $\mathrm{M}_{50}\left(6.5 \mathrm{M}_{\mathrm{S}}\right)$ for Revithoussa (Shield centre or Station 0, Table 1) is used as the criterion. Then the range $6.5 \pm 0.5$ or $6.07 .0 \mathrm{M}_{\mathrm{S}}$ should be the search parameter for the scenario. Therefore the results of strong motion records selected as scenario or "alert signals" for Revithoussa are as listed in Tables 4a-b. The Tables contain: time, depth, $\mathrm{M}_{\mathrm{b}}, \mathrm{M}_{\mathrm{L}}$ and $\mathrm{M}_{\mathrm{S}}$, epicentral intensity, station for the record, station intensity or site intensity, PGA_X, PGA_Y and PGA Z. Table 4a is from the strong-motion database of the National Observatory of Athens (NOA, Greece) and Table 4b is from the database of the Institute of Engineering Seismology \& Earthquake Engineering (ITSAK, Greece). The strong motion accelerograms $(\mathrm{N}-\mathrm{S}, \mathrm{E}-\mathrm{W}$ and $\mathrm{V})$ for the characteristic event (24 February 1981, 20:53:37 LT, 38.100 $\mathrm{N}$, $22.840^{\circ} \mathrm{E}, 6.5 \mathrm{M}_{\mathrm{S}}$. No. $157 \mathrm{a}$ in Table $4 \mathrm{a}$ ) are shown in Fig. 11a (No. 157a). Those for the rest of the characteris- tic events (Nos: 157b, 158, 284a, 284b, 83, 165a, 165b, 169a and $169 \mathrm{~b}$ in Tables $4 \mathrm{a}-\mathrm{b}$ ) are also shown in Fig. 11a-d. The strong motion records selected for Station 8 are the same as those for Station 0. Similarly, those selected for Stations 1-5, 6 and 7 are listed respectively in Tables $5 \mathrm{a}-\mathrm{b}, 6 \mathrm{a}-\mathrm{b}$ and 7 . And the strong motion accelerograms (N-S, E-W and V) for the characteristic events for the above stations are also illustrated in Figs. 11a-d.

\section{Conclusions}

These studies of local ground acceleration hazard based on MB, AM, TP and NTP models supply a common frame for estimation within the regional working area centred at Revithoussa, although different models provide different results. Among these, the NTP model is judged to be most reasonable because it is designed explicitly for Greek seismicity and its results are quite similar to the NEAK seismic estimation (Burton et al., 2003b). Our common estimation suggests that there are three main zones likely to be detected within the Shield regional working area. The results for extreme earthquake magnitudes also support the above estimation although some are not as detailed as the acceleration study. The main results are discussed as follows (Figs. 2-4, Figs. 6-11):

The most important zone to be monitored is the region NWW or W from this site at a relatively short distance (50 km or less) for the expected high PGA value distributions. This is the Gulf of Corinth (active normal faults) region. The PGA value based on NTP model with $90 \%$ probability of not being exceeded during the time period $T=50$ years (50-percentile, stiff soil sites) for data 1900 $1999\left(\mathrm{M}_{\mathrm{S}} \geq 5.5\right), \mathrm{PGA}_{\mathrm{NTP}}$, is in the range $\geq 250 \mathrm{~cm} \mathrm{~s}^{-2}$. The largest magnitude $\mathrm{M}_{50}$ expected over the time period of 50 years for the working area is in the range 6.7-6.8 and the values of the magnitude $\mathrm{M}_{\mathrm{p} 50}$ expected with a nonexceedance probability of $90 \%$ over the time period of 50 years are in the range 7.2-7.4. In addition, the corresponding parameters for the most perceptible earthquake magnitudes $\mathrm{M}_{\mathrm{VI}}, \mathrm{M}_{\mathrm{VII}}$ and $\mathrm{M}_{\mathrm{VIII}}$, corresponding to intensity VI, VII and VIII are in the respective ranges of 5.8-6.0, 6.2-6.4 and 6.4-6.6. This is the critical zone for early warning.

The second key region of seismicity likely to be detected is at an intermediate distance ( $100 \mathrm{~km}$ or more) from the Shield centre, the Hellenic seismic zone south or southeast from Peloponnisos. The corresponding parameters for estimations of local hazard are as follows: $\mathrm{PGA}_{\mathrm{NTP}}=250 \mathrm{~cm} \mathrm{~s}^{-2}$, $\mathrm{M}_{50}: 6.6, \mathrm{M}_{\mathrm{p} 50}: 7.0-7.2, \mathrm{M}_{\mathrm{VI}}: 6.2-6.8, \mathrm{M}_{\mathrm{VII}}: 6.4$ and $\mathrm{M}_{\mathrm{VIII}}: 6.8-7.0$.

The third region of seismicity likely to be detected would be northeast from the centre and is at a relatively long distance (about $150 \mathrm{~km}$ ). This is Limnos Island and neighboring region in the area influenced by the western extensions of the North Anatolian Fault zone. The corresponding parameters for the estimations of local hazard are as follows: $\mathrm{PGA}_{\mathrm{NTP}}=250 \mathrm{~cm} \mathrm{~s}^{-2}, \mathrm{M}_{50}: 7.0, \mathrm{M}_{\mathrm{p} 50}: 7.0, \mathrm{M}_{\mathrm{VI}}=6.8$, $\mathrm{M}_{\mathrm{VII}}=7.0$ and $\mathrm{M}_{\mathrm{VIII}}=7.1$. 


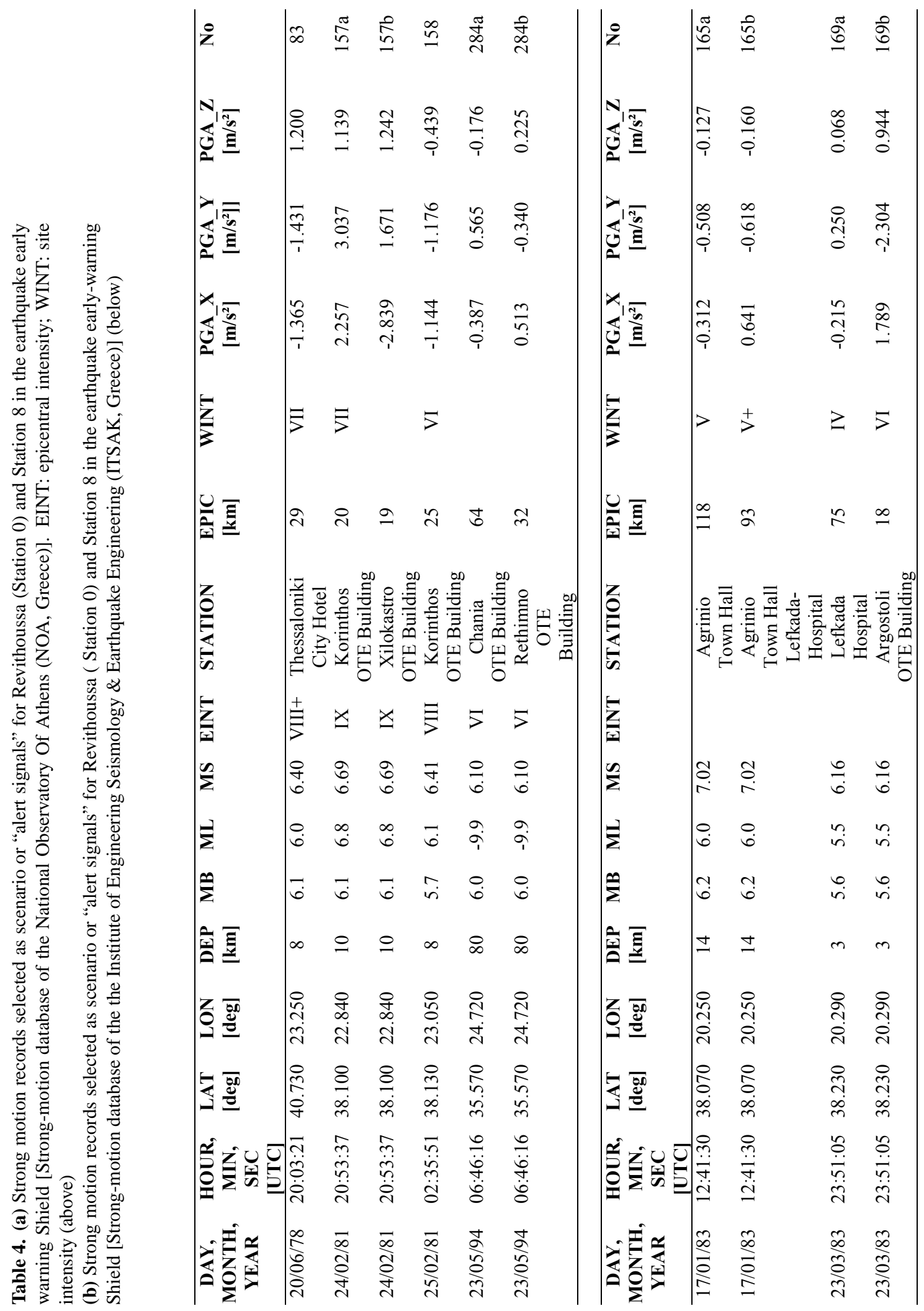




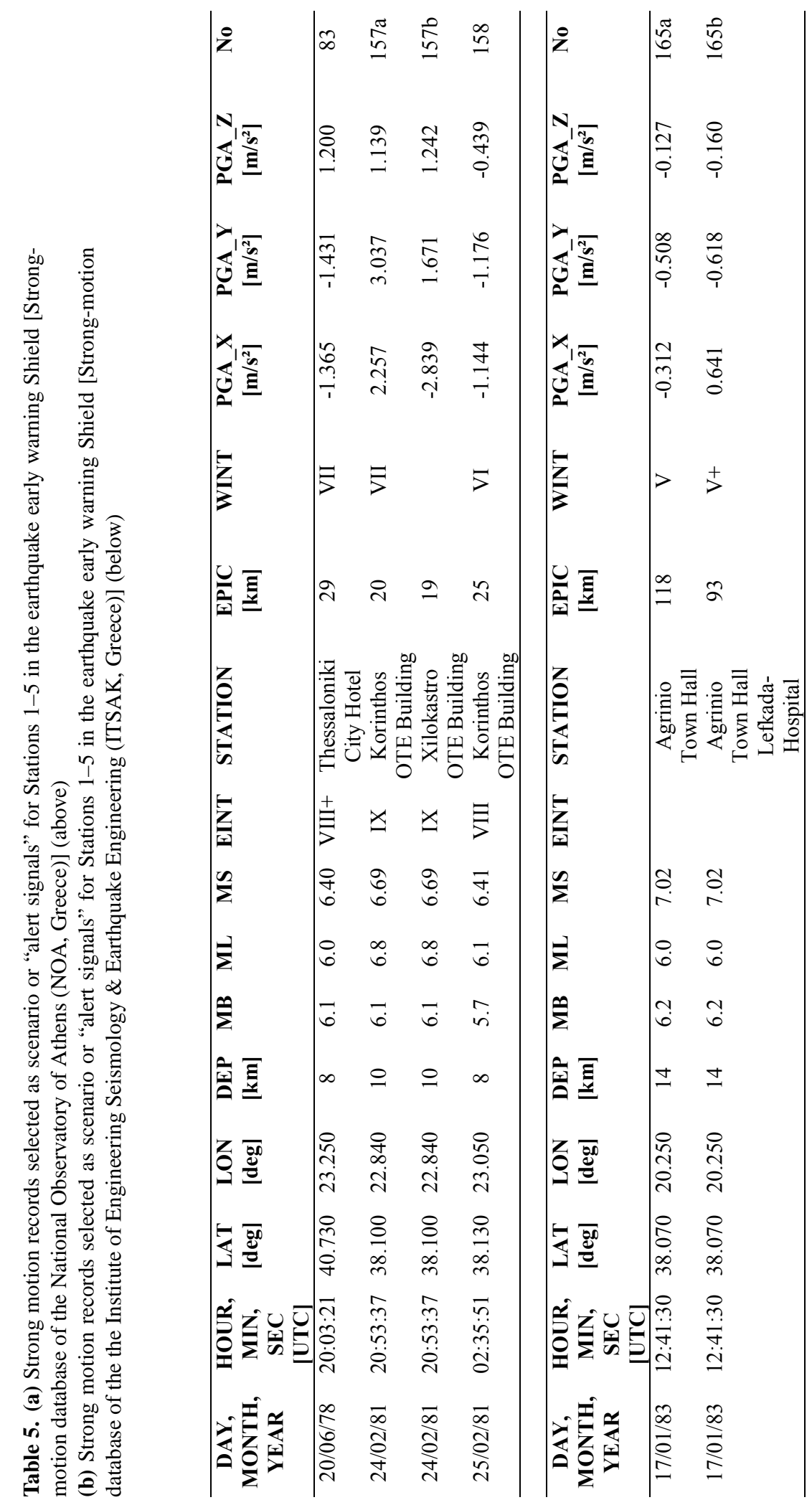



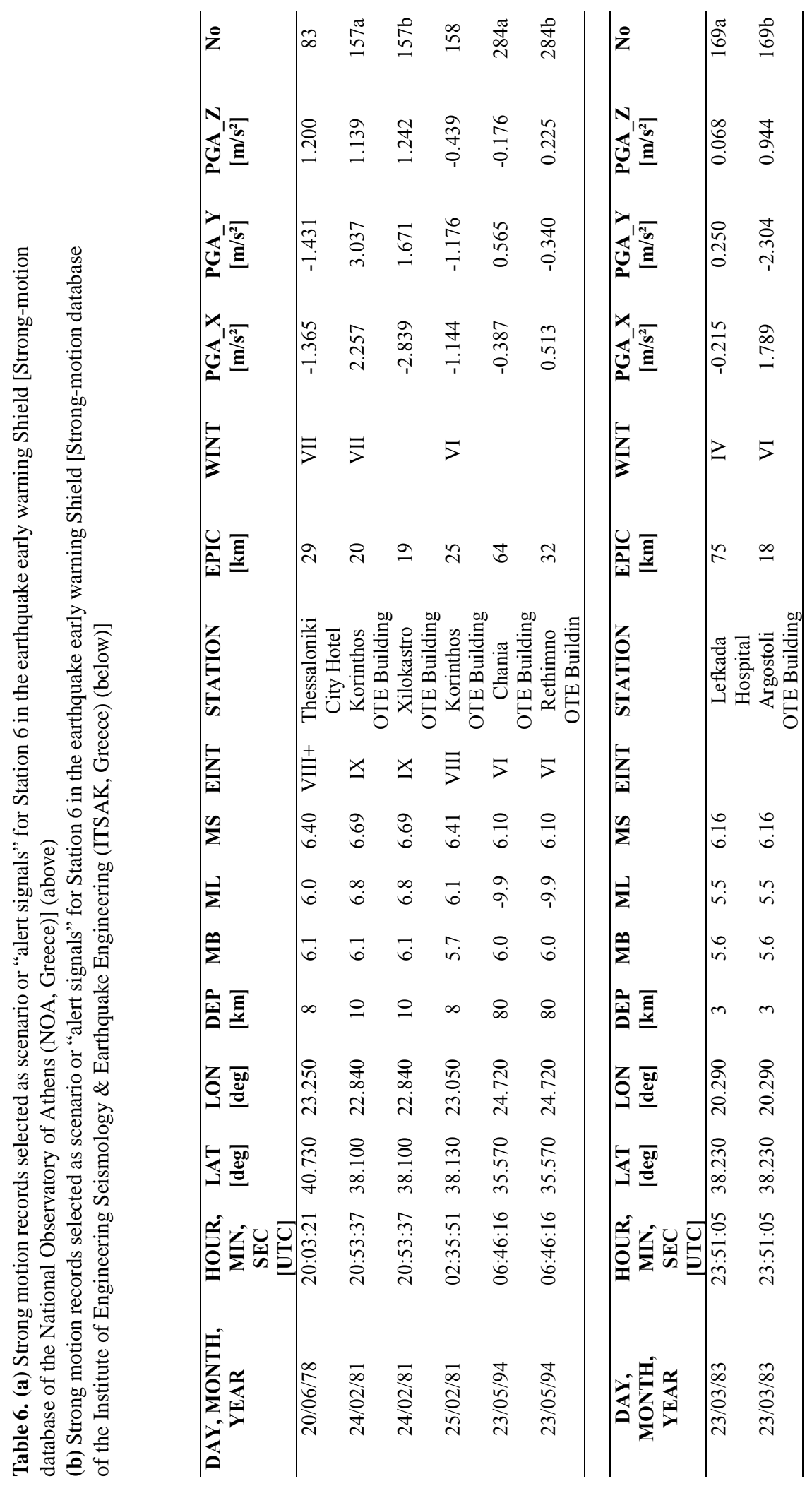

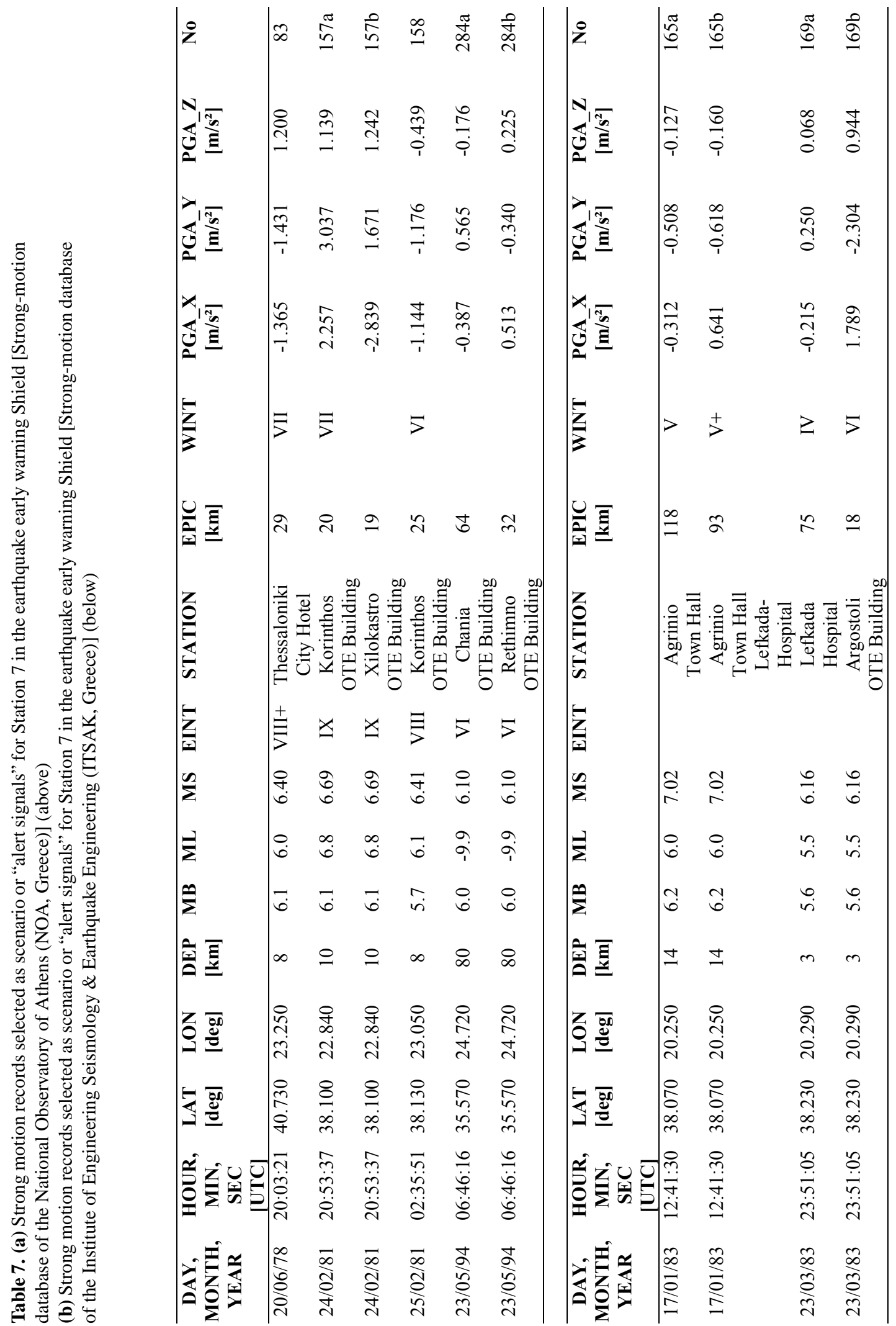
The corresponding parameters for estimations of local hazard for the Revithoussa centre itself are as follows: PGA $_{\mathrm{NTP}}: 203 \mathrm{~cm} \mathrm{~s}^{-2}, \mathrm{M}_{50}: 6.5, \mathrm{M}_{\mathrm{p} 50}: 6.9, \mathrm{M}_{\mathrm{VI}}: 5.8$, $\mathrm{M}_{\mathrm{VII}}: 6.1$ and $\mathrm{M}_{\mathrm{VIII}}: 6.4$.

The acceleration that has $90 \%$ probability of not being exceeded in 50 years based on the MB, TP, NTP, AM1 and AM2 models for all Shield seismic alert stations (Fig. 1a) of Revithoussa is listed in Table 3. Among these data, PGA $\mathrm{ATP}_{\mathrm{N}}$ for Stations 1-8 is respectively 139, 221, 197, 265, 197, 87, 274 and $71 \mathrm{~cm} \mathrm{~s}^{-2}$. The main parameters estimated to characterize the seismicity and hazard: the 50-year magnitude and at the $90 \%$ pnbe, $M_{50}$ and $M_{P 50}$, and the most perceptible earthquakes at intensities VI, VII and VIII with magnitudes $M_{V I}, M_{V I I}$ and $M_{V I I I}$ for all Shield seismic alert stations (Fig. 1) are also shown in Table 1.

The above results and parameters supply a full base characterizing the local seismic hazard for the regional working area centered at Revithoussa and earthquake monitoring stations in this system providing an early warning Shield for the Revithoussa hydrocarbon site and gas distribution centre.

The parameters for the scenario such as $\mathbf{M}_{50}$ listed in Table 1 are used as the criteria to select the characteristic events from the CD-ROM of the European strong-motion databank. The results for strong motion records selected as potential "alert signals" for Revithoussa and the Shield stations have been identified and are listed in Tables 4-7. The strong motion accelerograms (N-S, E-W and V) for these characteristic events for Revithoussa and the Shield stations are also illustrated in Fig. 11. These analyses of seismicity and seismic hazard in relation to the Shield centre and the remote sensor sites in the Shield network help characterize the hazard levels, seismic signals and ground vibration levels that might be observed during the creation of an alert situation at a station.

Acknowledgements. We are grateful to Christos Papaioannou (ITSAK), John Kalogeras (NOA) and Nick Ambraseys, who have provided access to earthquake strong motion data.

The SHIELDS project is supported by CEC Contract No. NNE5/1999/381.

\section{References}

Ahorner, L. and Rosenhaur, W.: Probability distribution of earthquake accelerations for the sites in Western Germany, in: Proc. 5th Europ. Conf. Earth. Eng., Istanbul, 1975.

Ambraseys, N. N.: The prediction of earthquake peak ground acceleration in Europe, Earthquake Eng. and Struct. Dynamics, 24, 467-490, 1995.

Ambraseys, N. N.: Measurement of strong ground motion in Europe (MASGE), in: Seismic Risk in the European Union (Vol. I), Proc. review meetings in Brussels 2-3 and 23-24 May 1996, ECSC-EC-EAEC Brussels, Luxembourg 1997, 195-217, edited by Ghazi, A. and Yeroyanni, M., 1997.

Ambraseys, N., Smit, P., Beradi, R., Rinalds, D., Cotton, F. and Berge-Thierry, C.: European strong-motion database documentation, European Council, Environment and Climate Research Programme, (CD-ROM), 2000.
Baba, A. B., Papadimitriou, E. E., Papazachos, B. C., Papaioannou, C. A., and Karakostas, B. G.: Unified local magnitude scale for earthquakes of south Balkan area, Pure appl. Geophys, 157, 765783, 2000.

Bath, M.: Seismicity of the Tanzania region. Tectonophysics, 27, 353-379, 1975.

Burton, P. W.: Perceptible earthquake in the United Kingdom, Geophys. J. R. Astro. Soc., 54, 475-479, 1978.

Burton, P. W.: Seismic risk in southern Europe through to India examined using Gumbel's third distribution of extreme values, Geophys. J. R. Astro. Soc., 59, 249-280, 1979.

Burton, P. W.: Variation in seismic risk parameters in Britain, Proceeding of the 2nd international symposium on the analysis of seismicity and on seismic hazard, Liblice, Czechoslovakia, May 18-23, 495-530, 1981.

Burton, P. W.: Pathways to seismic hazard evaluation: extreme and characteristic earthquakes in areas of low and high seismicity, Nat. Hazards 3, 275-291, 1990.

Burton, P. W. and Makropoulos, K. C.: Seismic risk of the Circumpacific earthquakes: II. Extreme values using Gumbel's third distribution and the relationship with strain energy release, Pure Appl. Geophys., 123, 849-869, 1985.

Burton, P. W., Qin, C., Tselentis, G.-A., and Sokos, E. A.: Extreme earthquake and earthquake perceptibility study in Greece and its surrounding area, Nat. Hazards, in press, 2003a.

Burton, P. W., Xu, Y., Tselentis, G.-A., Sokos, E. A. and Aspinall, W.: Strong ground acceleration seismic hazard in Greece and neighboring regions, Soil Dyn. EA, 23, 159-181, 2003b.

Burton, P. W., Xu, Y., Qin, C, Tselentis, G.-A., and Sokos, E. A.: Catalogue of seismicity in Greece, and the adjacent area for the twentieth century, Tectonophysics, in press, 2003c.

Donovan, N. C.: A statistical evaluation of strong motion data including the February 9, 1971, San Fernando earthquake, in: Proc. 5th World Conf. Earth. Eng., Rome, 1973.

Engdahl, E. R., Hilst, R. V. D., and Buland, R: Global teleseismic earthquake relocation with improved travel time and procedure for depth determination, Bull. seism. Soc. Am. 88, 722-743, 1998.

Espinosa Aranda, J. M., Jiménez, A., Ibarrola, G., Alcantar, F., Aguilar, A., Inostraza, M., and Maldonado, S.: Mexico city seismic alert system, Seismological Research Letters, 66, 42-53, 1995.

Erdik, M., Biro, Y. A., Onur, T., Sesatyan, K., and Birgoren, G.: Assessment of earthquake hazard in Turkey and neighbouring regions, Ann. Geofis. 42, 1125-1138, 1999.

Erdik, M., Fahjan, Y., Ozel, O., Alick, H., Mert, A., and Gul, M: Istanbul earthquake rapid response and the early warning system, Bull. European Earthq. Eng., in press, 2003.

Gumbel, E. J.: Statistics of extremes, Columbia Univ. Press, New York, 375 pp, 1966.

Katayama, T.: Statistical analysis of peak acelerations of recorded earthquake ground motions. Seisan-Kenkyu 26(1), 18-20, 1974.

Makropoulos, K. C. and Burton, P. W.: A catalogue of seismicity in Greece and adjacent areas, Geophys. J. R. astr. Soc. 65, 741-762, 1981.

Makropoulos, K. C. and Burton, P. W.: Seismic hazard in Greece, I. Magnitude recurrence, Tectonophysics, 117, 205-257, 1985a.

Makropoulos, K. C. and Burton, P. W.: Seismic hazard in Greece, II. Ground acceleration, Tectonophysics 117, 259-294, 1985 b.

Makropoulos, K. C., Drakopoulos, J. K., and Latousakis, J. B.: A revised and extended earthquake catalogue for Greece since 1900, Geophys. J. Int. Research Note, 98, 391-394, 1989. 
Margaris, B. N. and Papazachos, C. B.: Moment-magnitude relations based on strong-motion records in Greece, Bull. Seism. Soc. Am. 89, 442-455, 1999.

Margaris, B., Papazachos, C., Papaioannou, Ch., Theodulidis, N., Kalogeras, I., and Skarlatoudis, A.: Ground motion attenuation relations for shallow earthquakes in Greece, 12th European Conference on earthquake engineering, Paper reference 385, Elsevier Science Ltd., 2002.

NEAK: New Greek Seismic Resistant Code, Government Bull, No 613B/12-10-1992, 1992.

Orphal, D. L. and Lahoud, J. A.: Prediction of peak ground motion from earthquakes, Bull. seism. Soc. Am. 64, 1563-1574, 1974.

Papaioannou, Ch. A. and Papazachos, B. C.: Time-independent and time-dependent seismic hazard in Greece based on seismogenic source, Bull. seism. Soc. Am. 90, 22-33, 2000.

Papazachos, B. C. and Papaioannou, Ch. A.: The macroseismic field in the Balkan area, J. Seismology, 1, 181-201, 1997.

Papazachos, B. and Papazachou, C.: The earthquakes of Greece,
Ziti, P. \& Co., Thessaloniki, 1997.

Prérez, O.: Revised world seismicity catalog (1950-1997) for strong $\left(\mathrm{M}_{\mathrm{S}} \geq 6\right)$ shallow $(h \geq 70 \mathrm{~km})$ earthquakes, Bull. seism. Soc. Am. 89, 335-341, 1999.

Shah, H. C. and Movassate, M.: Seismic risk analysis - California state water project, in: Proc. 5th Europ. Conf. Earth. Eng., Istanbul, 1975.

Theodulidis, N. P. and Papazachos, B. C.: Dependence of strong ground motion on magnitude-distance, site geology and macroseismic intensity for shallow earthquakes in Greece: I, Peak horizontal acceleration, velocity and displacement, Soil Dyn. \& Earthquake Eng. 11, 387-402, 1992.

Theodulidis, N. P.: Personal Communication, 2001.

Trifunac, M. D.: Preliminary analysis of the peaks of strong earthquake ground motion dependence of peaks on earthquake magnitude, epicentral distance, and recording site conditions, Bull. seism. Soc. Am. 66, 189-219, 1976. 